\title{
Fiscal Foundations of Inflation: ImPERfECT KNOWLEDGE*
}

\author{
Stefano Eusepi ${ }^{\dagger} \quad$ Bruce Preston ${ }^{\ddagger}$
}

\begin{abstract}
This paper proposes a theory of the fiscal foundations of inflation based on imperfect knowledge and learning. Because imperfect knowledge breaks Ricardian equivalence, the scale and composition of the public debt matter for inflation. High and moderate duration debt generates wealth effects on consumption demand that impairs the intertemporal substitution channel of monetary policy: aggressive monetary policy is required to anchor inflation expectations. Counterfactual experiments conducted in an estimated model reveal that the US economy would have been substantially more volatile over the Great Inflation and Great Moderation periods if US debt levels had been those observed in Italy or Japan.
\end{abstract}

Keywords: Monetary and Fiscal Interactions, Learning Dynamics, Expectations Stabilization, Great Moderation, Great Inflation

JEL Codes: E32, D83, D84

${ }^{*}$ March 7, 2018. The authors are indebted to John Cochrane, Eric Leeper and our discussants Kosuke Aoki, Francesco Bianchi, Pedro Gomes-Porqueras, Chris Sims, Leopold von Thadden, the Editor and three anonymous referees for detailed comments and exchange of ideas. Klaus Adam, Leon Berkelmans, Bill Branch, Marc Giannoni, Sylvain Leduc, Fabio Milani, Ricardo Reis and John Williams are also thanked for useful discussions. The ideas contained herin also benefited from comments by seminar participants at numerous universities and conferences. We thank Sara Sahahanaghi and Rujun Han for excellent research assistance. The views expressed in the paper are those of the authors and are not necessarily reflective of views at the Federal Reserve Bank of New York or the Federal Reserve System. The usual caveat applies. Preston acknowledges research support from the Australian Research Council, under the grant FT130101599.

${ }^{\dagger}$ Federal Reserve Bank of New York; stefano.eusepi@ny.frb.org

${ }^{\ddagger}$ University of Melbourne; bruce.preston@unimelb.edu.au. 
"Fiscal policy is extremely important in determining what fraction of total national income is spent by government and who bears the burden of that expenditure. By itself, it is not important for inflation."

Milton Friedman

"Persistent high inflation is always and everywhere a fiscal phenomenon."

Thomas Sargent

\section{INTRODUCTION}

This paper presents theory and evidence that incomplete knowledge and learning created fiscally-driven inflation in the United States. Permitting beliefs to depart from those consistent with rational expectations equilibrium leads to deviations from Ricardian equivalence, to create causal links among the paths of government debt, taxes and inflation. When debt levels and maturity structures are as observed in many countries, the links are sufficiently strong to hinder a central bank's pursuit of price stability. Holdings of the public debt generate wealth effects on aggregate demand which compromise the standard intertemporal substitution channel of monetary policy.

These findings contrast sharply with the conventional view of stabilization policy — see Clarida, Gali, and Gertler (1999). This view posits strongly neutral fiscal policy: changes in the size and maturity composition of nominal government liabilities have no impact on inflation. This clean separation of monetary and fiscal policy pervades contemporary thinking on monetary-fiscal interactions, and is a core tenet of monetarism. Our paper argues that in general such sharp predictions do not emerge under imperfect knowledge, and are unlikely to be a feature of any actual economy. Special cases of the model, which include rational expectations, deliver Friedman's (1970) dictum that "inflation is always and everywhere a monetary phenomenon". But they are just that: special cases, giving insight reminiscent of Tobin's (1980) claim that "Ricardian equivalence is fundamental, perhaps indispensable, to monetarism". In general our paper shares with Sargent and Wallace (1981) and Leeper (1991) the idea that inflation can be a fiscal phenomenon, but does not require the choice of fiscal financing to be a source of inflation - fiscally-driven inflation arises even when a policy maker commits to raise taxes to finance debt. ${ }^{1}$

At the heart of our paper is the realistic assumption that agents face fundamental uncertainty about long-run fiscal and monetary policy. Consider standing at the peak of the Great Inflation in the late 1970s. It is simply implausible to suppose agents at that time correctly anticipated subsequent macroeconomic developments, such as the Volcker disinflation; the long-term decline in inflation and inflation expectations; and the formal adoption of an inflation target by the Federal Reserve some 30 years later. ${ }^{2}$ Ten-year inflation and interest-rate expectations from professional surveys tell us they didn't. Incorrect expecta-

\footnotetext{
${ }^{1}$ See also Sims (1994), Woodford (1996) and Cochrane (2001), seminal references on the fiscal theory of the price level.

2Interpret "correctly anticipated" to mean agents correctly assigned probabilities to future states and dates. A now substantial literature studies monetary-fiscal policy interactions under such assumptions see, among others, Davig and Leeper (2006), Ascari, Florio, and Gobbi (2017) and Bianchi and Melosi (2017).
} 
tions led to public debt that was incorrectly priced relative to what a hypothetical agent would pay, who anticipates these developments and predicts a decline in interest rates over subsequent decades. We show forecast errors of this kind lead to departures from Ricardian equivalence and to wealth effects on aggregate demand.

A simple endowment economy provides conditions under which imperfect knowledge and learning generate non-neutralities of fiscal policy. In contrast to rational expectations, where long-run expectations are time-invariant and consistent with the objectives of policy, agents infer the long-run mean of inflation and taxes using a simple statistical model, adjusting their beliefs in response to short-term forecast surprises. Wealth effects arise from shifting views of the present value of taxation, relative to the perceived market value of public debt holdings. ${ }^{3}$ They are more important when forecast errors are to some degree self-fulfilling a property called 'self-referentiality' by Marcet and Sargent (1989) — which occurs precisely when fiscal policy is characterized by high debt of moderate duration. We show how these self-referential dynamics are destabilizing and require a more aggressive monetary response to inflation to anchor inflation expectations, relative to Ricardian economies. By itself, fiscal policy is important for inflation, contrary to Friedman's proposition on monetary-fiscal interactions. Only when debt is zero on average, or of very short or long maturity, does the model predict "inflation is always and everywhere a monetary phenomenon".

The theory underscores the knife-edge results of Leeper (1991), which modern monetary economics inherits, are special, and that imperfect knowledge blurs the clean separation of monetary and fiscal policy. While rational expectations analysis predicts qualitative changes in equilibria as a central bank chooses its policy response to inflation to be more or less aggressive (in New Keynesian monetary models whether or not the Taylor principle is satisfied), wealth effects are always present in our model. And while the fiscal theory of the price level has the same basic mechanism, our result obtains even under the conventional assignment of policy in which monetary policy stabilizes the price level, and tax policy stabilizes the public debt. Perhaps more importantly, the model predicts wealth effects get larger as the average scale of issued debt increases. The fiscal theory predicts the opposite. ${ }^{4}$

That more heavily indebted economies constrain monetary policy certainly resonates with public pronouncements of policy makers, and is arguably a pressing practical issue in the aftermath of the 2007-2009 global recession, which sharply raised public debt-to-GDP ratios in many countries. Using an empirical medium-scale dynamic stochastic general equilibrium model of the US economy, we establish the quantitative relevance of the theory. The sample spans the Great Inflation of the 1970s and the Great Moderation of the 1980s and 1990s. The data from these periods exhibit substantial low-frequency movement, providing a genuine test of our theory. The econometrics identifies how macroeconomic disturbances drive various objects that are central to the proposed mechanism, and specifically how they shape long-run beliefs, through short-run forecast errors. The empirical model explains the survey data on long-term expectations well, establishing that learning dynamics are important.

Having identified the central mechanism, we show how disturbances determine perceived wealth effects and aggregate demand. The historical narrative that emerges from our analysis

\footnotetext{
${ }^{3}$ Imperfect knowledge re-weights standard wealth and substitution effects of consumption demand. In this way the theory is distinct from the fiscal theory of the price level. See also Adam, Beutel, and Marcet (2013) for a discussion of the consequences of such re-weighting for asset pricing.

${ }^{4}$ See, for example, Beck-Friis and Willems (2017).
} 
has much in common with Smets and Wouters (2007). Differences concern the relative importance of certain disturbances, as beliefs, being state variables, soak up low-frequency variation present in macroeconomic data. The estimated model predicts persistent nonRicardian effects from fiscal policy. However, because the US economy had a low average debt-to-GDP ratio over the sample, substitution effects dominate wealth effects.

Counterfactual analysis shows that the impulse and propagation mechanisms are fundamentally different in high-debt economies. Responses to shocks are more persistent and often amplified. Disturbances engender wealth effects that offset the standard channel of monetary policy operating through intertemporal substitution. Consider an unexpected tightening in monetary policy. Substitution effects generate a fall in inflation and output. But departures from Ricardian equivalence induce additional wealth effects on consumption. The low inflation and high-debt issuance associated with higher nominal interest rates both lead to revisions in subjective beliefs about long-run means that over-estimate future taxes and under-estimate the value of government debt, relative to model-consistent expectations. These negative wealth effects are offset by a substantial fall in the present discounted value of taxes arising from higher expected interest rates. The net effect on perceived wealth is positive, which reduces the efficacy of a policy tightening, leading to smaller, though more persistent, declines in inflation and output.

Imperfect knowledge generates wealth effects which undermine inflation control. Additional counterfactual experiments demonstrate macroeconomic volatility over the sample would have been substantially higher, had the US had average debt equal to currents levels, or levels observed in many other countries. Much of the decline in volatility observed in the Great Moderation would disappear. Furthermore, the recessions associated with the Volcker disinflation and the technology boom of the 1990s would have witnessed deflation, with monetary policy constrained by the zero lower bound on interest rates. Implications for contemporary policy debate are immediate.

\section{An Endowment ECONOMY}

This section presents a simple flexible-price endowment economy with long-term nominal bonds. Rather than forming rational expectations, agents have incomplete knowledge about the economic environment: behaving as econometricians, they update their subjective expectations using data from the economic system in which they operate. We introduce learning using the anticipated-utility approach of Kreps (1998) and Sargent (1999). The analysis follows Marcet and Sargent (1989) and Preston (2005), solving for optimal decisions conditional on current beliefs.

\subsection{HouseHolds}

A continuum of households maximize future expected discounted utility

$$
\hat{E}_{t}^{i} \sum_{T=t}^{\infty} \beta^{T-t} \frac{C_{T}(i)^{1-\sigma}}{1-\sigma}
$$

where $\sigma>0,0<\beta<1$ and $C_{t}(i)$ denotes household- $i$ consumption in period $t$. The operator $\hat{E}_{t}^{i}$ denotes the beliefs at time $t$ held by each household $i$, described below. Households 
have access to two types of nominal assets supplied by the government: one-period debt, $B_{t}^{s}$, with price $P_{t}^{s}$; and a more general portfolio of debt, $B_{t}^{m}$, with price $P_{t}^{m}$. Following Woodford (1998, 2001), the latter asset pays coupons $\rho^{T-(t+1)}$ for $T>t$ and $0 \leq \rho \leq 1$. The value of such an instrument issued in period $t$ in any future period $t+j$ is $\rho^{j} P_{t+j}^{m}$. The asset can be interpreted as a portfolio of infinitely many bonds, with weights along the maturity structure given by $\rho^{T-(t+1)}$. Varying the parameter $\rho$ varies the average maturity of the asset. ${ }^{5}$ For example, when $\rho=0$ the portfolio comprises one-period debt; and when $\rho=1$ the portfolio comprises consol bonds.

Define $P_{t}$ as the price level at period $t$. Letting $b_{t}^{s}(i) \equiv B_{t}^{s}(i) / P_{t}$ and $b_{t}^{m}(i) \equiv B_{t}^{m}(i) / P_{t}$, the expression $\mathbb{W}_{t}(i) \equiv P_{t}^{s} b_{t}^{s}(i)+P_{t}^{m} b_{t}^{m}(i)$ defines household $i$ 's real wealth. The budget constraint is

$$
\mathbb{W}_{t}(i) \leq R_{t}^{m} \pi_{t}^{-1} \mathbb{W}_{t-1}(i)+\left(R_{t-1}^{s}-R_{t}^{m}\right) \pi_{t}^{-1} P_{t-1}^{s} b_{t-1}^{s}(i)+y_{t}(i)-\tau_{t}(i)-C_{t}(i)
$$

where $R_{t}^{m}=\left(1+\rho P_{t}^{m}\right) / P_{t-1}^{m}$ and $R_{t-1}^{s}=1 / P_{t-1}^{s}$ denote realized returns from holding each asset, with the latter implicitly defining the period nominal interest rate, the instrument of central bank policy. Each period households receive a stochastic endowment, $y_{t}(i)$, an i.i.d. random variable, and pay lump-sum taxes $\tau_{t}(i)$. Finally, agents face a no-Ponzi constraint

$$
\lim _{T \rightarrow \infty} \hat{E}_{t}^{i}\left(\prod_{s=0}^{T-t} R_{t+s}^{m} \pi_{t+s}^{-1}\right)^{-1} \mathbb{W}_{T}(i) \geq 0
$$

where $\pi_{t}=P_{t} / P_{t-1}$.

To summarize, households choose sequences $\left\{C_{T}(i), \mathbb{W}_{T}(i), b_{T}^{s}(i)\right\}_{T=t}^{\infty}$ to maximize utility, $(1)$, subject to $(2)$ and (3), given initial wealth $\mathbb{W}_{t-1}(i)$ and their beliefs regarding the evolution of the endowment, taxes and asset returns. Conditional on beliefs, optimality requires (2) and (3) hold with equality and satisfaction of

$$
C_{t}^{-\sigma}(i)=\hat{E}_{t}^{i}\left[R_{t}^{s} \frac{C_{t+1}^{-\sigma}(i)}{\pi_{t+1}}\right] ; \text { and } C_{t}^{-\sigma}(i)=\hat{E}_{t}^{i}\left[R_{t+1}^{m} \frac{C_{t+1}^{-\sigma}(i)}{\pi_{t+1}}\right]
$$

the Euler equations corresponding to the two assets.

\subsection{Monetary AND FisCAL POLICY}

The central bank implements monetary policy using the interest-rate rule

$$
R_{t}^{s}=R^{s} \pi_{t}^{\phi_{\pi}}
$$

where $\phi_{\pi} \geq 0$ and $R^{s}$ the steady-state gross interest rate. The steady-state inflation rate is zero. The fiscal authority finances exogenous purchases, $G_{t}$, assumed here to be zero in each period, by issuing public debt and levying lump-sum taxes. One-period debt, $B_{t}^{s}$, is in zero supply, while $B_{t}^{m}>0$ in all periods $t$. Imposing the first restriction gives the flow budget constraint of the government

$$
P_{t}^{m} b_{t}^{m}=\pi_{t}^{-1} b_{t-1}^{m}\left(1+\rho P_{t}^{m}\right)-\tau_{t},
$$

\footnotetext{
${ }^{5}$ This structure can evaluate the effects of debt maturity with the addition of a single state variable.
} 
where each agent faces the same tax burden, $\tau_{t}(i)=\tau_{t}$ for $i \in[0,1] .{ }^{6}$ The rule

$$
\tau_{t}=\tau+\phi_{b} P^{m}\left(b_{t-1}^{m}-b^{m}\right)+\bar{\tau}_{t},
$$

determines tax policy, where $\phi_{b} \geq 0$ and $\tau$ and $P^{m} b^{m}$ denote the steady-state level of taxes and debt. Taxes respond to changes in the real amount (at face value) of issued debt and an i.i.d. exogenous shock $\bar{\tau}_{t} \cdot{ }^{7}$

\subsection{MARKET CLEARING AND EQUILIBRIUM}

The analysis studies a symmetric equilibrium in which all households are identical, though they do not know this to be true. Given that households have identical initial asset holdings, preferences, endowment, taxes and beliefs, and face common constraints, they make identical state-contingent decisions. Equilibrium requires all goods and asset markets to clear. The former requires the aggregate restriction

$$
\int_{0}^{1} C_{t}(i) d i=C_{t}=\int_{0}^{1} y_{t}(i) d i
$$

where $C_{t}$ denotes aggregate consumption demand. The latter requires

$$
\int_{0}^{1} B_{t}^{s}(i) d i=0 \text { and } \int_{0}^{1} B_{t}^{m}(i) d i=B_{t}^{m}
$$

with $B_{-1}^{s}(i)=0$ and $B_{-1}^{m}(i)=B_{-1}^{m}>0$ for all households $i \in[0,1]$. Equilibrium is a sequence of prices $\left\{P_{t}, P_{t}^{m}, R_{t}^{s}\right\}$ and allocations $\left\{C_{t}(i), B_{t}^{m}(i), \tau_{t}\right\}$ satisfying individual optimality and market clearing conditions, given $y_{t}(i)$ for $i \in[0,1]$.

The policy regime. The policy regime has 'active' monetary policy, satisfying the Taylor principle $\phi_{\pi}>1$, and 'passive' fiscal policy, $\beta^{-1}-1<\phi_{b}<\beta^{-1}+1$. Under rational expectations, this implies a locally unique bounded equilibrium in which nominal liabilities have no monetary consequences; the size and duration of public debt do not affect inflation — see Leeper (1991). Globally, the policy regime displays multiple equilibria under rational expectations. The New Keynesian literature discusses these equilibria extensively, including deflationary traps and explosive equilibria. ${ }^{8}$ We restrict our analysis to the neighborhood of the locally unique equilibrium with zero inflation. Introducing incomplete knowledge and learning dramatically changes the properties of this 'good' equilibrium. Studying the global properties of the model is left to future research.

\section{Aggregate Dynamics}

Employ a first-order approximation in the neighborhood of the non-stochastic steady state of zero inflation. For any variable $k_{t}$ denote $\hat{k}_{t}=\ln \left(k_{t} / k\right)$ the $\log$ deviation from steady

\footnotetext{
${ }^{6}$ Generalizing to permit heterogeneity in tax obligations, where these obligations remain in fixed proportion, delivers identical results.

${ }^{7}$ The results do not change if taxes respond instead to the changing value of nominal debt.

${ }^{8}$ See for example Benhabib, Schmitt-Grohe, and Uribe (2001), Woodford (2003) and Cochrane (2011).
} 
state with the exception of the short-term interest rate, $\hat{\imath}_{t}=\ln \left(R_{t}^{s} / R^{s}\right)$, and debt and taxes defined as

$$
\tilde{b}_{t}^{m}=\frac{P^{m}\left(b_{t}^{m}-b^{m}\right)}{y} \text { and } \tilde{\tau}_{t}=\frac{\tau_{t}-\tau}{y} .
$$

Optimal consumption decision. Household optimization yields the demand function

$$
\begin{aligned}
\hat{C}_{t}= & (1-\beta) \hat{y}_{t}-\sigma^{-1} \beta \hat{E}_{t} \sum_{T=t}^{\infty} \beta^{T-t}\left(\hat{\imath}_{T}-\hat{\pi}_{T+1}\right)+ \\
& +\left(\beta^{-1}-1\right) \times\left\{\left(\tilde{b}_{t-1}^{m}-\delta \hat{\pi}_{t}+\delta \beta \rho \hat{P}_{t}^{m}\right)+\beta \hat{E}_{t} \sum_{T=t}^{\infty} \beta^{T-t}\left[\delta\left(\hat{R}_{T+1}^{m}-\hat{\pi}_{T+1}\right)-\tilde{\tau}_{T}\right]\right\}
\end{aligned}
$$

where $\sigma^{-1}$ denotes the consumption intertemporal elasticity of substitution, and $\delta=P^{m} b^{m} / y$ measures the steady-state debt-to-output ratio. Because we analyze a symmetric equilibrium in which households have identical decision problems and beliefs, so $\hat{E}_{t}=\hat{E}_{t}^{i}$ for every $i \in[0,1]$, drop the index $i$.

Net of the endowment, the sum of the expected path of the real interest rate (top line) and a constant fraction of perceived net wealth from holding bonds (bottom line) determines consumption demand. The first term represents the standard transmission mechanism of monetary policy in a Ricardian economy, which operates through the intertemporal substitution of consumption. The second term introduces a new channel of policy, and is referred to as the 'non-Ricardian', or 'net wealth', component of consumption demand. It comprises three parts: the real market value of debt holdings, the present value of real returns from holding debt (purchased in the current period), and the expected present value of lump-sum taxes. In a rational expectations equilibrium these terms sum precisely to zero. Under imperfect knowledge, subjective expectations of returns and taxes may imply the public debt is perceived as net wealth, even in the absence of distortionary taxation. Model dynamics depend on the relative strength of the standard and non-Ricardian components of demand, referred to loosely as 'substitution' and 'wealth' effects. The intertemporal elasticity of consumption, $\sigma^{-1}$, the debt-to-output ratio, $\delta$, and the average duration of debt, measured by $\rho$, regulate the relative importance of these sources of demand.

Departures from Ricardian equivalence are quite plausible in a heterogeneous agent economy. Only when agents know they are the representative agent would they conclude the government budget constraint implies the present discounted value of their individual taxes equals the value of their individual bond holdings. Indeed, a central result of Evans, Honkapohja, and Mitra (2012) — which provides a detailed discussion of the conditions under which Ricardian equivalence will hold under non-rational beliefs - is Ricardian equivalence will obtain if agents believe the present value of their individual taxes equals the value of their individual bond holdings. Under our information assumptions, there is no reason this need be true.

Asset pricing. A log-linear approximation to the first-order conditions for asset holdings yields the no-arbitrage restriction

$$
\hat{\imath}_{t}=\hat{E}_{t} \hat{R}_{t+1}^{m}
$$


and the price of the bond portfolio

$$
\hat{P}_{t}^{m}=-\hat{E}_{t} \sum_{T=t}^{\infty}(\beta \rho)^{T-t} \hat{\imath}_{T}
$$

The expected present discounted value of all future one-period interest rates, where the discount factor is given by $\beta \rho$, prices the debt portfolio. This is an example of the expectations hypothesis of the yield curve. The quantity $(1-\beta \rho)^{-1}$ gives the portfolio's average duration. The assumption of symmetric beliefs ensures the existence of a unique equilibrium bond price. This paper abstracts from asset pricing issues arising from financial market participants having heterogeneous non-nested information sets implied by our assumptions. For simplicity, each agent supposes that they are the marginal trader in all future periods when determining desired asset allocations. Equilibrium affirms this supposition as all agents are identical. $^{9}$

Government debt. Combining a linear approximation to the government budget constraint, (5), the tax rule, (6) and the bond price, (10), yields

$$
\tilde{b}_{t}^{m}=\left(\beta^{-1}-\phi_{b}\right) \tilde{b}_{t-1}^{m}-\bar{\tau}_{t}-\delta\left[\left(\beta^{-1}-(1-\rho) \phi_{\pi}\right) \pi_{t}-(1-\rho) \rho \beta \hat{E}_{t} \sum_{T=t}^{\infty}(\beta \rho)^{T-t} \hat{\imath}_{T+1}\right]
$$

where $\left|\beta^{-1}-\phi_{b}\right|<1$. The evolution of debt depends on expectations about the future path of monetary policy. The degree to which policy expectations affect debt, equivalently taxes, depends both on the size of debt, $\delta$, and on its average duration, $\rho$. For very low and very long-debt maturities these effects are small, and vanish in the case of one-period debt, $\rho=0$, and consol bonds, $\rho=1$. With low duration, the bond price only reflects changes in the short-term interest rate, not interest-rate beliefs. With high duration, the price of debt reflects changes in policy expectations, in their entirety, with no effect on debt issuance and taxes. ${ }^{10}$ In contrast, for intermediate duration, shifting policy expectations affect both the price and quantity of debt.

\section{InFormation, LEARNing AND NON-RICARDiAn EFFECTS}

\subsection{Beliefs}

Specifying beliefs completes the model. Households have incomplete knowledge about the true structure of the economy. They observe only their own objectives, constraints and

\footnotetext{
${ }^{9}$ How to handle asset pricing in an incomplete markets setting with subjective beliefs requires further study. There are two sources of complication. First, with multiple assets, projected returns under arbitrary subjective beliefs may not satisfy no-arbitrage. In a first-order approximation, such beliefs are inconsistent with bounded portfolio decisions. We therefore follow Sinha (2016) and impose no-arbitrage consistent beliefs by using the price relation (10). Second, the fact that this model is technically one in which agents have heterogeneous information sets, raises questions about asset price determination and, specifically, which agent is the marginal trader of the asset. Again, we do not solve this complicated issue, and simply assume each agent supposes they are the marginal trader, which is true in equilibrium. Progress on this second issue has been made by Adam and Marcet (2011), who show how to determine equity prices in an incomplete markets model with short-sale constraints, and subjective beliefs of the kind studied here.

${ }^{10}$ As the average duration of the government debt portfolio increases, the quantity of newly issued debt in any period declines. In the limit of consol debt, the price effect therefore vanishes.
} 
realizations of aggregate quantities and prices that are exogenous to their decision problems and beyond their control. They have no knowledge of the beliefs, constraints and objectives of other agents in the economy: even though their decision problems are identical, they do not know this to be true. This and incomplete knowledge of the prevailing policy regime, implies that they do not know the equilibrium evolution of inflation, debt and taxes.

Rational Expectations equilibrium. To anchor ideas, the model has a unique bounded rational expectations equilibrium

$$
\pi_{t}=-\sigma \phi_{\pi}^{-1} \hat{y}_{t}
$$

and

$$
\tilde{b}_{t}^{m}=\left(\beta^{-1}-\phi_{b}\right) \tilde{b}_{t-1}^{m}+\delta\left(\beta^{-1}-(1-\rho) \phi_{\pi}\right) \sigma \phi_{\pi}^{-1} \hat{y}_{t}-\bar{\tau}_{t} .
$$

Inflation is a linear function of the endowment process and independent of fiscal variables. The equilibrium is Ricardian — debt has no monetary consequences - exemplifying Friedman's (1970) dictum "inflation is always and everywhere a monetary phenomenon" and his proposition on monetary-fiscal interactions that "by itself, fiscal policy is not important for inflation".

Learning about long-term drifts. To learn about equilibrium dynamics, agents employ a simple linear econometric model in the variables $z_{t}=\left(\begin{array}{ccc}\hat{\pi}_{t} & \tilde{b}_{t}^{m} & \tilde{\tau}_{t}\end{array}\right)^{\prime}$. For expositional purposes, we assume agents understand the monetary policy rule so they need not forecast the interest rate independently of inflation. The results do not depend on this assumption, which we drop in the empirical analysis. The forecasting model is

$$
z_{t}=\omega_{t-1}+\Phi z_{t-1}+e_{t}
$$

where $e_{t}$ is a noise term. The model nests the minimum-state-variable rational expectations solution which satisfies

$$
\omega^{*}=\mathbf{0}_{3 \times 1} ; \Phi^{*}=\left[\begin{array}{ccc}
0 & 0 & 0 \\
0 & \beta^{-1}-\phi_{b} & 0 \\
0 & \phi_{b} & 0
\end{array}\right] .
$$

We assume agents only face uncertainty about long-run conditional means, captured by $\omega_{t-1}$, with beliefs about slope coefficients satisfying $\Phi=\Phi^{*}$. This places emphasis on the role of imperfect knowledge about long-run policy objectives, such as the inflation target or tax obligations attached to government debt holdings. The model then permits use of standard linear methods, particularly valuable for subsequent analytical and empirical work, while giving a non-trivial role to shifting long-term expectations as a source of dynamics. Importantly, these beliefs are consistent with low-frequency properties of survey forecast data from household and professional forecasters — see, for example, Kozicki and Tinsley (2012) and Crump, Eusepi, and Moench (2015). Eusepi and Preston (2011) also adduce evidence that, when solving learning models under the anticipated-utility assumption, incomplete information about constants generate the quantitatively relevant self-referential dynamics, not learning about slope coefficients.

Expectations and recursive estimation. In period $t$ agents form expectations using the forecasting model based on data available up to period $t-1 .{ }^{11}$ Denoting period- $t$ beliefs

\footnotetext{
${ }^{11}$ To avoid a difficult simultaneity problem, agents use previous-period estimates when forming current forecasts. This is standard in the learning literature. Beliefs are a state variable.
} 
$\hat{\omega}_{t-1}=\left(\begin{array}{lll}\hat{\omega}_{t-1}^{\pi} & \hat{\omega}_{t-1}^{b} & \hat{\omega}_{t-1}^{i}\end{array}\right)$, use (14) to evaluate expectations for taxes and inflation as ${ }^{12}$

$$
\begin{aligned}
\hat{E}_{t} \sum_{T=t+1}^{\infty} \beta^{T-t} \tilde{\tau}_{T+1} & =\frac{1}{1-\beta}\left(\hat{\omega}_{t-1}^{\tau}+\hat{\omega}_{t-1}^{b}\right)+\beta^{-1} \tilde{b}_{t}^{m} \\
\hat{E}_{t} \sum_{T=t}^{\infty}\left(\beta \rho^{j-1}\right)^{T-t} \hat{\pi}_{T+1} & =\frac{1}{1-\beta \rho^{j-1}} \hat{\omega}_{t-1}^{\pi}, j=1,2 .
\end{aligned}
$$

The recursive algorithm

$$
\begin{aligned}
\hat{\omega}_{t} & =\hat{\omega}_{t-1}+g_{t} \eta_{t} \\
\eta_{t} & =z_{t}-\left(\hat{\omega}_{t-1}+\Phi^{*} z_{t-1}\right)
\end{aligned}
$$

updates time- $t$ estimates, $\hat{\omega}_{t}$, where $\eta_{t}$ is the prediction error. ${ }^{13}$

These beliefs embody a defining property of all signal-extraction and filtering problems: perceived drifts in macroeconomic data (i.e. long-term conditional expectations) are tied to short-term forecast errors. Observing short-term fluctuations, agents infer low-frequency movements in aggregate data. The gain parameter $g_{t}$ governs the sensitivity of the estimated drift to short-term surprises. When $g_{t}=t^{-1}$ the updating rule, (17), is recursive least squares. When $g_{t}=\bar{g}$, the updating rule is a constant-gain algorithm, discounting past observations more heavily. An observation $n$-periods old receives weight $(1-\bar{g})^{n}$. A constant $\bar{g}$ insures against potential shifts in the structure of the economy (i.e. a policy regime shift). Sargent, Williams, and Zha (2006) interpret this as a steady-state Kalman filter in which the prior on the variance of innovations, $e_{t}$, in (14), is proportional to the prior on the variance of low-frequency drift. ${ }^{14}$ The next section explicates reasons to study both assumptions. The literature on learning and imperfect information widely uses algorithms of the form (17), which can parsimoniously capture imperfect knowledge about policy — see Orphanides and Williams (2005), Eusepi and Preston (2010, 2012) and Kozicki and Tinsley (2012).

\subsection{Self-Referential Dynamics and Wealth efFects}

The data-generating process implicitly defines a mapping between subjective beliefs, $\hat{\omega}_{t-1}$, and the actual drift describing dynamics. Substituting the forecasts, (15) and (16), into the consumption and debt equations, (9) and (11), and imposing market clearing in the goods market, $C_{t}=y_{t}$, gives the true data-generating process

$$
\hat{\pi}_{t}=-\frac{\beta-\phi_{\pi}^{-1}}{1-\beta} \hat{\omega}_{t-1}^{\pi}-\sigma \phi_{\pi}^{-1} \hat{y}_{t}+n_{w, t}
$$

\footnotetext{
${ }^{12}$ Recall, forecasts of the interest rate are constructed using the monetary policy rule, so $\hat{E}_{t} \hat{\imath}_{T}=\phi_{\pi} \hat{E}_{t} \pi_{T}$ for $T>t$.

${ }^{13}$ Formally, this belief structure combined with the optimal decision rules provides the anticipated-utility solution of the model. For a detailed discussion of how this solution concept relates to the internal rationality approach of Adam and Marcet (2011) the reader is referred to Eusepi and Preston (2016). The anticipated utility approach assumes agents do not take into account future revisions of beliefs when making current decisions but are otherwise fully optimal, whereas the internal rationality approach considers Bayesian beliefs which take account of such revisions.

${ }^{14}$ Sargent, Williams, and Zha (2006) and Eusepi, Giannoni, and Preston (2015) discuss this, and provide examples of more general specifications of Kalman gain matrices.
} 
The first term captures the only channel through which beliefs affect inflation in a Ricardian economy: intertemporal substitution of consumption. The second term involving beliefs, $n_{w, t}$, measures the perceived net wealth effects from holding bonds which satisfy

$$
n_{w, t}=\sigma\left(\beta^{-1}-1\right) \delta \times\left[\frac{\beta-\phi_{\pi}^{-1}}{1-\beta}-\frac{\beta \rho^{2}}{1-\beta \rho}-\frac{(1-\rho) \beta \rho}{1-\beta \rho}\right] \hat{\omega}_{t-1}^{\pi}-\sigma \phi_{\pi}^{-1}\left(\hat{\omega}_{t-1}^{b}+\hat{\omega}_{t-1}^{\tau}\right),
$$

revealing that shifting views about long-term inflation, debt and tax obligations can in principle lead to movements in perceived net wealth. The term in brackets comprises three effects from shifting views about future inflation: the first two are the effect on projected real returns and the direct effect on the debt price, the capital value of existing debt holdings in equation (9). The debt evolution equation

$$
\tilde{b}_{t}^{m}=\left(\beta^{-1}-\phi_{b}\right) \tilde{b}_{t-1}^{m}-\delta \times\left[\left(\beta^{-1}-(1-\rho) \phi_{\pi}\right) \pi_{t}-\frac{(1-\rho) \beta \rho}{1-\beta \rho} \phi_{\pi} \hat{\omega}_{t-1}^{\pi}\right]-\bar{\tau}_{t}
$$

reveals the third term arises from the government's flow budget constraint: variations in the current price of long-term debt cause new debt issuance which shift expected taxes.

Equations (19) and (21), with the updating rule for beliefs, (17), characterize equilibrium. Together they clarify the self-referential dynamics of inflation and debt. Beliefs affect the actual evolution of inflation, debt and taxes, which in turn affect future beliefs: partially self-fulfilling beliefs induce time-varying drift in the true data-generating process. We determine conditions for self-referential dynamics to produce fluctuations in perceived net wealth $n_{w, t}$, to impact the macroeconomy. Anticipating subsequent results, drifting beliefs lead to departures from Ricardian equivalence by affecting the equilibrium value of the government debt. What follows explores various dimensions of this model property. While we derive results in a simple endowment economy, they provide indispensable intuition for the empirical model.

The endowment and tax shocks, $\hat{y}_{t}$ and $\bar{\tau}_{t}$, drive forecast errors. Short-term forecast errors drive long-run beliefs. To study the dynamic properties of the model we can characterize, without loss of generality, the evolution of both beliefs and realized outcomes assuming the system starts at rational expectations. ${ }^{15}$ The first result establishes tax innovations do not generate non-Ricardian consumption demand effects. They satisfy Ricardian Equivalence.

Result 1. Tax shocks $\bar{\tau}_{t}$ do not induce any perceived wealth effects: conditional on tax shocks only, $\hat{\pi}_{t}=n_{w, t}=0$ in every period.

Proof. Assume $\hat{\omega}_{t-1}^{\pi}=\hat{\omega}_{t-1}^{\tau}=\hat{\omega}_{t-1}^{b}=0$. From (19) and (20) the tax shock has no immediate impact on inflation, $\hat{\pi}_{t}=0$. From the updating rule (17), debt and tax beliefs are given by $\hat{\omega}_{t}^{\tau}=g_{t} \bar{\tau}_{t}$ and $\hat{\omega}_{t}^{b}=-g_{t} \bar{\tau}_{t}$, so that $\hat{\omega}_{t}^{b}=-\hat{\omega}_{t}^{\tau}$. Moreover, as $\hat{\pi}_{t}=0, \omega_{t}^{\pi}=0$. This implies $n_{w, t+1}=0$ and $\hat{\pi}_{t+1}=0$. It then follows from (17) in all subsequent periods $T \geq t+1, \hat{\omega}_{T}^{\pi}=0$ and $\hat{\omega}_{T}^{b}=-\hat{\omega}_{T}^{\tau}$ and, therefore, $n_{w, T}=0$ and $\hat{\pi}_{T}=0$.

This perhaps surprising result appears at odds with the central thesis of the paper: that departures from Ricardian equivalence generate wealth effects which constrain inflation policy. While subsequent analysis renders this concern premature, Result $\mathbf{1}$ helps identify

\footnotetext{
${ }^{15}$ Assuming arbitrary initial beliefs induces some additional temporary dynamic behavior.
} 
the properties required to have fiscal effects on inflation. In response to a lump-sum tax shock, beliefs about debt and taxes move in exactly offsetting ways to leave net-worth and inflation unaffected. There can be no self-fulfilling dynamics for debt and taxes because only inflation beliefs matter for the quantity of issued debt.

Of course, this result depends on specific model assumptions, such as the belief structure and class of tax rules. However, given our assumptions are conventional in the literature, the paper focuses on the fiscal effects of other disturbances driving macroeconomic dynamics. Given Result 1, the remainder of this section assumes $\bar{\tau}_{t}=\hat{\omega}_{t}^{\tau}=0$ without loss of generality. ${ }^{16}$ We now identify which properties of debt engender self-referential dynamics, and positive wealth effects on consumption demand.

Result 2. Consider the simple endowment economy driven by shocks $\hat{y}_{t}$. Then: i) with $\delta=0$ or $\rho=0,1$ perceived wealth effects are exactly zero, $n_{w, t}=0$, in every period; and ii) with $\delta>0$ and $\rho \in(0,1)$ an inflation surprise at time $t$ (resulting from variations in $\hat{y}_{t}$ ), implies

$$
n_{w, t+1}=\frac{\beta \rho(1-\rho)}{1-\beta \rho} \sigma \delta \times \hat{\omega}_{t}^{\pi},
$$

generating self-referential beliefs.

Proof. Again assume $\omega_{t-1}^{\pi}=\omega_{t-1}^{\tau}=\omega_{t-1}^{b}=0$. Start with a zero-debt economy, $\delta=0$. The true data-generating process for debt is

$$
\tilde{b}_{T}^{m}=\left(\beta^{-1}-\phi_{b}\right) \tilde{b}_{T-1}^{m} \text { for } T \geq t .
$$

From the updating rule, (17), and the expression for net wealth, (20), $\hat{\omega}_{T}^{b}=n_{w, T}=0$ for $T \geq t$. Consider now the average duration of debt. For $\rho=0,1$ from (21) we have

$$
\tilde{b}_{T}^{m}=\left(\beta^{-1}-\phi_{b}\right) \tilde{b}_{T-1}^{m}-\delta\left(\beta^{-1}-(1-\rho) \phi_{\pi}\right) \hat{\pi}_{T} \text { for } T \geq t .
$$

From the updating rule $(17), \omega_{T}^{b}=-\delta\left(\beta^{-1}-(1-\rho) \phi_{\pi}\right) \omega_{T}^{\pi}$ for $T \geq t$. Substituting this restriction in (19) for $\rho=0,1$ yields $n_{w, T}=0$ for $T \geq t$. Finally, consider $\delta>0$ and $\rho \in(0,1)$. From the updating rule (17) a surprise in inflation leads to $\omega_{t}^{b}=-\delta\left(\beta^{-1}-(1-\rho) \phi_{\pi}\right) \omega_{t}^{\pi}$. Substituting into (19) and (20) gives

$$
\begin{aligned}
n_{w, t+1} & =\frac{\beta \rho(1-\rho)}{1-\beta \rho} \sigma \delta \hat{\omega}_{t}^{\pi} ; \quad \hat{\pi}_{t+1}=-\left[\frac{\beta-\phi_{\pi}^{-1}}{1-\beta}-\frac{\beta \rho(1-\rho)}{1-\beta \rho} \sigma \delta\right] \hat{\omega}_{t}^{\pi}, \\
\tilde{b}_{t+1}^{m} & =\left(\beta^{-1}-\phi_{b}\right) \tilde{b}_{t}^{m}-\delta \times\left[\left(\beta^{-1}-(1-\rho) \phi_{\pi}\right) \hat{\pi}_{t+1}-\frac{(1-\rho) \beta \rho}{1-\beta \rho} \phi_{\pi} \hat{\omega}_{t}^{\pi}\right] .
\end{aligned}
$$

This leads to a revision in both inflation and debt beliefs in period $t+2$, in turn affecting actual variables and future beliefs.

Equation (22) captures the 'wedge' between the value of outstanding debt and the present discounted value of taxes. Revisiting equation (21) reveals these effects operate through the

\footnotetext{
${ }^{16}$ Tax beliefs only move in response to tax disturbances, which themselves satisfy Ricardian equivalence. Long-run conditional expectations which display more general dependency on short-run forecast errors (different gains attached to forecast revisions of each variable), or a tax rule that responds to expected macroeconomic developments, would predict departures from Ricardian equivalence.
} 
price of newly issued debt and its impact of debt issuance and taxes; we refer to them as valuation effects. In absence of valuation effects of the public debt which generate movements in net wealth, debt evolves independently of inflation beliefs, which prevents near self-fulfilling tax expectations. This happens despite debt and inflation beliefs being revised in response to a shock, because in equilibrium changes in the present discounted value of taxes are exactly matched by changes in the real value of debt and its expected returns, leaving net wealth unchanged. With positive debt and intermediate maturity structures $\rho \in(0,1)$, shifts in expected interest rates affect debt issuance and tax expectations which, in turn, impact consumption demand and inflation. Expectations become then partially self-fulfilling, with implications for economic stability and the conduct of monetary policy. ${ }^{17}$ The magnitude of these effects is proportional to the size of debt-to-output ratio and inversely related to the consumption intertemporal elasticity of substitution.

Marcet and Sargent (1989) and Evans and Honkapohja (2001) demonstrate an ordinary differential equation describes the limiting behavior of beliefs. This equation encodes a mapping from the perceived drift $\hat{\omega}_{t}$ in (14) to the actual drift in the true data-generating process, and is derived by substituting (19) and (21) into the updating rule (17) for debt and inflation drifts. The learning literature refers to the implied dynamics as the "mean dynamics'. In compact terms, the ordinary differential equation is

$$
\left[\begin{array}{c}
\hat{\omega}^{\pi} \\
\hat{\omega}^{b}
\end{array}\right]=(T-I)\left[\begin{array}{c}
\hat{\omega}^{\pi} \\
\hat{\omega}^{b}
\end{array}\right]
$$

where the coefficients on beliefs in (19) and (21) determine the respective elements of the matrix $T .{ }^{18}$ The fixed point of $(23)$ is the rational expectations equilibrium $\omega^{*}=0$. The self-referential behavior of the economy depends on the interaction between the perceived drift and the realized drift. This in turn depends on the properties of the matrix $T$.

Two kinds of stability result can be established. If the fixed point of the ordinary differential equation is stable, implying all eigenvalues have negative real parts, then: 1) for decreasing-gain algorithms, $g_{t}=t^{-1}$, as $g_{t} \rightarrow 0$ beliefs $\hat{\omega}_{t}$ converge point-wise to rational expectations equilibrium $\omega^{*}$. Such convergence is called expectational stability; and 2) for constant-gain algorithms, $g_{t}=\bar{g}$, and $\bar{g}$ sufficiently small, $\hat{\omega}_{t}$ converges to a limiting distribution centered on $\omega^{*}$ — see Evans and Honkapohja (2001). The analysis exploits the first stability result to understand the interactions of monetary and fiscal policy, and the constraints long-term debt places on inflation control; and the second stability result, premised on the first, to explore model dynamics and the empirical relevance of our theory. The conditions for expectational stability apply to a broad range of adaptive learning algorithms, of which least-squares learning is but one example. In this sense the results are quite general see, again, Evans and Honkapohja (2001). The following proposition summarizes the main theoretical result.

Proposition 1. Consider the policy regime defined by: $\phi_{\pi}>1 ; \beta^{-1}-1<\phi_{b}<\beta^{-1}+1$. Then: i) Under rational expectations, neither $\delta$ nor $\rho$ affect inflation; and ii) under learning,

\footnotetext{
${ }^{17}$ Note for one-period debt, $\rho=0$, the monetary policy rule is critical to the finding of no wealth effects. Policy rules that respond to inflation expectations generate revised beliefs which feed back into debt dynamics, breaking Ricardian equivalence. The appendix contains further discussion.

${ }^{18}$ Details are available in the appendix.
} 
provided $\delta>0$ and $\rho \neq 0,1$ convergence to rational expectations occurs if and only if

$$
\phi_{\pi}>\max \left[1,\left(1+(1-\beta)\left(1-\sigma \times \delta \frac{(1-\rho) \rho \beta}{1-\rho \beta}\right)\right)^{-1}\right]
$$

Corollary 1. Under learning, with $\delta=0$ or $\rho=0,1$ convergence to rational expectations always occurs.

For a given average maturity of debt, higher average levels of indebtedness require more aggressive monetary policy. For a given scale of public debt, variation in the average maturity of public debt engenders non-monotonic constraints on monetary policy. The relative strength of substitution and wealth effects arising from debt revaluation determine expectational dynamics. When wealth effects are weak, the Taylor principle, $\phi_{\pi}>1$, is necessary and sufficient to promote stability, as shown by Bullard and Mitra (2002) and Preston (2005). Suppose a positive inflation surprise leads to an upward revision in the inflation drift. Policy responds by increasing the real interest rate, which depresses consumption demand and inflation and induces downward updates in the drift towards rational expectations. However, sufficiently strong wealth effects impair this process. Higher inflation reduces real debt on impact and leads to a downward revision in long-term debt and tax expectations, leading to net positive wealth effects from holding bonds. ${ }^{19}$ Higher consumption demand hinders the downward adjustment of inflation expectations. Proposition 1 shows that if wealth effects are sufficiently large there is no convergence.

\section{Fiscal Policy and Inflation: Quantitative Evaluation}

The idea that more heavily indebted economies constrain monetary policy certainly resonates with public pronouncements of policy makers. But does the endowment economy analysis identify mechanisms that are quantitatively relevant? This section provides an assessment in the context of an empirical medium-scale dynamic stochastic general equilibrium model of the US economy. A core goal of the empirical model is to identify how macroeconomic disturbances drive various objects that are central to the proposed mechanism. A comprehensive understanding of the mechanism therefore requires an integrated treatment of how disturbances affect beliefs, perceived wealth effects, and ultimately aggregate demand.

For this reason the empirical model accounts for the joint dynamics of both standard macroeconomic time series and also survey data on expectations. The sample period spans both the Great Inflation of the 1970s and the Great Moderation of the 1980s and 1990s. The data from these periods exhibit substantial low-frequency movement in various macroeconomic time series, providing a direct evaluation of the consistency of our theory with basic data facts. Our model permits understanding the source of low-frequency movement in long-term expectations, and specifically the role of fiscal policy in unanchoring inflation expectations in the 1970s, and the subsequent decline in macroeconomic volatility during the Great Moderation. Furthermore, the model has implications for recent debate on the

\footnotetext{
${ }^{19}$ The initial increase in net wealth in response to an inflation surprise in shown analytically in Result 2. The appendix also provides plots of the model's impulse response functions.
} 
factors underlying the Great Moderation. Research emphasizes changes in the conduct of monetary policy or changes in the volatility of economic disturbances - often referred to as good policy versus good luck. ${ }^{20}$ A notable feature of these analyses is the absence of fiscal variables: to what extent was the Great Moderation the result of good fiscal policy?

\subsection{A Medium-Scale Model}

The model is New Keynesian, similar in spirit to Giannoni and Woodford (2004), extended to include multiple-maturity debt. The appendix provides details.

Firms. A continuum of monopolistically competitive firms $f$ each produce differentiated goods, $Y_{t}(f)$, using the linear production function in labor, $N_{t}(f)$,

$$
Y_{t}(f)=Z_{t} N_{t}(f) e^{A_{t}}
$$

where $Z_{t}$, labor-augmenting technical progress, evolves deterministically as $Z_{t}=\gamma Z_{t-1}$, with $\gamma>1$, and $e^{A_{t}}$ denotes a zero-mean stationary technology shock with an i.i.d. error term: $A_{t}=\rho_{a} A_{t-1}+\sigma_{a} \epsilon_{t}^{a} \cdot{ }^{21}$ Each firm faces a Kimball (1995) demand curve

$$
\Psi^{\prime}\left(\frac{Y_{t}(f)}{Y_{t}} ; \theta_{p, t}\right)=\Psi^{\prime}(1) \frac{P_{t}(f)}{P_{t}}
$$

where $\Psi(\cdot)$ is a concave function with $\Psi(1)=1 ; \ln \left(\theta_{p, t} / \theta_{p}\right)=\sigma_{\theta_{p}} \epsilon_{t}^{\theta_{p}}$ denotes a mean-zero i.i.d markup shock; $P_{t}$ the aggregate price index. ${ }^{22}$ Equilibrium in the goods market yields $Y_{t}=$ $C_{t}+G_{t}$ where $Y_{t}$ is aggregate output, $C_{t}$ is the consumption aggregator and $G_{t}$ denotes an exogenous government spending shock defined as: $\hat{G}_{t}=\ln \left(G_{t} / G\right)=\rho_{G} \hat{G}_{t-1}+\sigma_{g} \epsilon_{t}^{G}+\sigma_{g a} \sigma_{a} \epsilon_{t}^{a}$. Following Smets and Wouters (2007), empirical fit motivates the dependence of the spending shock on technology. Firms solve a Rotemberg-style price-setting problem, choosing a price $P_{t}(f)$ to maximize the expected discounted value of profits ${ }^{23}$

$$
\hat{E}_{t}^{f} \sum_{T=t}^{\infty} Q_{t, T} \Gamma_{T}(f)
$$

taking wages, $W_{t}$, the aggregate price level and technology as given, with profits defined by

$$
\Gamma_{t}(f)=\frac{P_{t}(f)}{P_{t}} Y_{t}-\frac{W_{t}}{P_{t}} N_{t}(f)-\frac{\Phi_{t}^{p}}{2}\left(\frac{P_{t}(f)}{P_{t-1}(f)}-\bar{\Pi}_{t}^{p}\right)^{2}
$$

and

$$
\Phi_{t}^{p}=\phi_{p} C_{t} ; \quad \bar{\Pi}_{t}^{p}=\pi^{1-\iota_{p}} \pi_{t-1}^{\iota_{p}} .
$$

\footnotetext{
${ }^{20}$ Important contributions include, inter alia, Clarida, Gali, and Gertler (2000), Lubik and Schorfheide (2004), Sims and Zha (2006), Primiceri (2005), Justiniano and Primiceri (2008) and Fernandez-Villaverde, Guerron-Quintana, and Rubio-Ramirez (2010).

${ }^{21}$ We normalize all i.i.d disturbances $\epsilon_{t}^{i}$ to have mean zero and unit variance.

${ }^{22}$ The assumed demand function captures real rigidities affecting the firm pricing decision.

${ }^{23}$ Because we consider a first-order approximation to equilibrium dynamics, this is equivalent to assuming Calvo pricing.
} 
These final terms ensure adjustment costs scale appropriately to the consumption aggregator, given technological progress, and apply only to price movements relative to a price index, which is a weighted combination of the previous-period's and steady-state inflation, with $\phi_{p}>0$ and $0<\iota_{p}<1$. Firms value future profits according to the marginal rate of substitution evaluated at aggregate consumption

$$
Q_{t, T}=\beta^{T-t} \frac{P_{t}}{P_{T}} \frac{\Lambda_{T}}{\Lambda_{t}}
$$

for $T \geq t$, where $\Lambda_{t}$ is the marginal value of wealth determined in the household's problem. ${ }^{24}$

Households. A continuum of households $i$ maximize intertemporal utility

$$
\hat{E}_{t}^{i} \sum_{T=t}^{\infty} \beta^{T-t} \frac{c_{H, T}(i)^{1-\sigma} \nu\left(N_{T}(i)\right)}{1-\sigma}
$$

where

$$
C_{H, t}=\frac{C_{t}(i)}{Z_{t}}-b \frac{C_{t-1}}{Z_{t-1}}
$$

with $\sigma>1$ and $0<b<1$, and the convex function $\nu(\cdot)$ with properties described in the appendix. $^{25}$ Households have market power in the supply of differentiated labour inputs, and face demand curve

$$
N_{t}(i)=\left(\frac{W_{t}(i)}{W_{t}}\right)^{-\theta_{w, t}} N_{t}
$$

where $\theta_{w, t}>1$ denotes the time-varying elasticity of demand across differentiated labor inputs, which evolves according to $\hat{\theta}_{t}^{w}=\ln \left(\theta_{t}^{w} / \theta^{w}\right)=\rho_{\theta_{w}} \hat{\theta}_{t-1}^{w}+\sigma_{\theta_{w}} \epsilon_{t}^{\theta_{w}}$. Households set their wage rate, subject to quadratic adjustment costs, and supply the quantity of hours demanded by firms at that price.

The household's flow budget constraint is

$C_{t}(i)+\mathbb{W}_{t}(i) \leq R_{t}^{m} \pi_{t}^{-1} \mathbb{W}_{t-1}(i)+\left(R_{t-1}^{s}-R_{t}^{m}\right) P_{t-1}^{s} b_{t-1}^{s}(i)-\frac{\Phi_{t}^{w}}{2}\left(\frac{W_{t}(i)}{W_{t-1}(i)}-\bar{\Pi}_{t}^{w}\right)^{2}+\Gamma_{t}-T_{t}$

defining

$$
\Phi_{t}^{w}=\phi_{w} C_{t} ; \quad \bar{\Pi}_{t}^{w}=(\pi \gamma)^{\iota_{w}}\left(\pi_{t-1} \gamma_{t-1}\right)^{1-\iota_{w}}
$$

where $\phi_{w}>0$ and $0<\iota_{w}<1$. The variables $\mathbb{W}_{t}(i), R_{t}^{s}, R_{t}^{m}, P_{t}^{s}, b_{t}^{s}(i)$ and $T_{t}$ are defined as in the endowment economy. Finally, $\Gamma_{t}$ denotes profits received from an equal equity share of each differentiated firm. As for the price-setting problem, the adjustment costs on wages scale to be consistent with balanced growth, and to ensure newly set wages reflect recent goods price inflation and productivity growth.

Policy. The central bank implements monetary policy using the interest-rate rule

$$
R_{t}=\left(R_{t-1}\right)^{\rho_{i}}\left[R\left(P_{t} / P_{t-1}\right)^{\phi_{\pi}} X_{t}^{\phi_{x}}\right]^{1-\rho_{i}} e^{m_{t}}
$$

\footnotetext{
${ }^{24}$ Given that each agent makes identical decisions, this corresponds to the stochastic discount factor of a hypothetical representative agent.

${ }^{25}$ We specify preferences in terms of detrended consumption so that the real return in steady state is not affected by the elasticity of intertemporal substitution of consumption.
} 
where $\phi_{\pi}, \phi_{x} \geq 0, R$ the steady-state gross interest rate, and $X_{t}$ denotes the model-theoretic output gap. ${ }^{26}$ Interest-rate policy exhibits inertia and responds to deviations of inflation and output from steady-state levels. ${ }^{27}$ The steady-state inflation rate is zero; $m_{t}=\sigma_{m} \epsilon_{t}^{m}$ denotes a mean-zero i.i.d monetary shock. The flow budget constraint of the government is

$$
P_{t}^{m} B_{t}^{m}=B_{t-1}^{m}\left(1+\rho P_{t}^{m}\right)-P_{t} S_{t}
$$

where the real structural surplus is

$$
S_{t}=T_{t} / P_{t}-G_{t}
$$

The government levies lump-sum taxes, $T_{t}$, using the rule

$$
\frac{T_{t}}{Z_{t} P_{t}}-\bar{\tau}=\rho_{\tau}\left(\frac{T_{t-1}}{Z_{t-1} P_{t-1}}-\bar{\tau}\right)+\left(1-\rho_{\tau}\right) \phi_{\tau_{l}}\left(l_{t}-l\right)+\bar{\tau}_{t}
$$

where $\bar{\tau}$ is the normalized steady-state level of taxes, $l_{t}=B_{t-1}^{m}\left(1+\rho P_{t}^{m}\right) /\left(Z_{t-1} P_{t-1}\right)$ a measure of real government liabilities in period $t$, with $l$ its steady-state value. The appendix shows that using the face value of debt in the policy rule, rather than the market value of debt, leaves the results largely unchanged. Policy satisfies $\phi_{\tau_{l}} \geq 0$ and $0<\rho_{\tau}<1$, consistent with empirical work by Davig and Leeper (2006). Finally, the mean-zero tax shock satisfies $\bar{\tau}_{t}=\rho_{\bar{\tau}} \bar{\tau}_{t-1}+\sigma_{\bar{\tau}} \epsilon_{t}^{\bar{\tau}}$.

\subsection{Beliefs And Model Solution}

As in the simple model, we specify beliefs as a linear econometric model of the form (14), which nests the first-order approximation of the stationary rational expectations equilibrium. The model includes all variables which households and firms must forecast to make consumption, pricing and wage-setting decisions. These are: inflation, interest rates, taxes, dividends, wages, hours and the quantity of long-term debt. The only uncertainty about the statistical properties of these variables is the mean. As common in the learning literature, assume agents have perfect knowledge of the stationary exogenous shocks: perceived drifts for these variables are zero in every period. Using a constant gain, the rule (17) updates the drifts for endogenous variables.

Conditional on beliefs, we follow the expositional logic of the endowment economy and solve for optimal decisions under the anticipated-utility approach — see Preston (2005) and Eusepi and Preston (2016) for discussion. The empirical model extends Orphanides and Williams (2005), Milani (2007) and Slobydan and Wouters (2012a, 2012b) to environments in which agents make optimal decisions. Details of the first-order approximation to the model, and the derivation of the anticipated-utility solution, are in the appendix.

\footnotetext{
${ }^{26}$ This is defined as the ratio of output to the level of output that would occur under flexible wage and prices, under rational expectations.

${ }^{27}$ The analysis eschews the study of optimal policy to give emphasis to the interaction of monetary policy with various dimensions of fiscal policy. See Eusepi, Giannoni, and Preston (2015) for an analysis of optimal policy in a closely related model.
} 


\subsection{The Data and State-Space Representation}

To estimate model parameters we use nine US time series. Five are standard macroeconomic variables: the log-difference of the GDP deflator, the output gap (as measured by Congressional Budget Office), the three-month TBill interest rate, the real hourly compensation growth (measured from nonfarm business sector), and the tax revenue-to-GDP ratio as defined in Traum and Yang (2011). ${ }^{28}$ The remaining four times series are short- and long-term professional forecasts of the three-month TBill and GDP deflator growth. We use these series to discipline beliefs. For each of these two variables, the mean one-quarter-ahead forecast from the Survey of Professional Forecasters measures short-term forecasts; the mean fiveto-ten-years-ahead forecast from Blue Chip Economics measure long-term forecasts. These data permit direct inference on the mapping of short-run forecast errors into long-run beliefs.

The estimation uses quarterly data over the period 1968Q4 to 2007Q3. ${ }^{29}$ The beginning of the sample coincides with the first available survey forecast of GDP deflator inflation. The end of the sample is chosen to exclude the period when the policy rate is at the zero lower bound. Handling the modeling complications of the crisis period is beyond the scope of the paper. Short-term forecasts for the TBill are only available starting in 1981Q3, while long-term forecasts are available at bi-annual frequency starting in 1984Q1.

The first-order approximation of the structural equations combines with the specification of beliefs to give a time-invariant linear state-space model

$$
\mathbb{Z}_{t}=F(\Theta) \mathbb{Z}_{t-1}+Q(\Theta) \epsilon_{t}
$$

where $\Theta$ is a vector of parameters and $\mathbb{Z}_{t}$ is the state vector of variables, including perceived drifts. $^{30}$ The measurement equation

$$
\mathbb{Y}_{t}=\mu_{t}(\Theta)+H_{t}(\Theta) \mathbb{Z}_{t}+o_{t}
$$

attaches four measurement errors, $o_{t}$, to survey forecasts. The vector $\mu_{t}$ contains the long-run mean of the observables. The matrix $H_{t}$ and vector $\mu_{t}$ are time varying because of missing observations. We estimate the model using Bayesian inference. ${ }^{31}$

\subsection{Parameter Estimates}

Calibrated parameters. The long-run mean of inflation and the short-term interest rate in $\mu$ are set equal to $2 \%$ and $4 \%$. This implies a short-term real interest rate of $2 \%$ over the sample, which Crump, Eusepi, and Moench (2015) show is consistent with survey data. The quarterly growth rate of technical progress $\gamma=1.004$ matches the average real GDP per-capita growth over the sample. The household's discount factor is $\beta=0.99$. Given

\footnotetext{
${ }^{28}$ In the model, the output gap is: $Y_{t} / Z_{t}$. Tax revenues are the sum of federal personal current tax, federal taxes on corporate income and federal contributions to social insurance. Together with GDP and inflation, these data are from the National Income and Product Accounts released by the Bureau of Economic Analysis. The compensation data are released by the Bureau of Labor Statistics.

${ }^{29}$ We include a training sample of 4 quarters, starting in the first quarter of 1968.

${ }^{30}$ Details are in the appendix.

${ }^{31}$ We compute the posterior parameter distribution using the Metropolis-Hastings algorithm. Details are in the appendix.
} 
technical progress, this implies a steady-state real rate of $5.6 \%$, which differs to the mean short-term rate in the observation equation. In the model, steady-state returns on shortand long-term bonds are the same: $R^{m}=R$. This equality fails to hold in the data: our chosen discount factor roughly matches a mean nominal interest rate on government debt of about $7 \%{ }^{32}$ The choice reflects our focus on measuring the wealth effects from holding bonds which are directly linked to the steady-state discount rate — recall equation (9). ${ }^{33}$ Regarding fiscal policy, the average maturity of debt in sample is 5.5 years giving $\rho=0.97$; the debt-to-output ratio is set to $30 \%$, in terms of annualized quarterly GDP, giving $\delta=1.2$; and the spending-to-output ratio is $G / Y=0.16 .{ }^{34}$ Finally, we fix two parameters not well identified by the data. The steady-state elasticity of demand for labor is $\theta^{w}=5$, implying a steady-state markup of $25 \%$. The Frisch elasticity of labor supply, $\phi_{n}$, is 0.6 , consistent with micro-evidence.

Prior Distributions. Tables 1 and 2 provide details on the priors. The priors for the exogenous shock processes are the same across variables. The persistence of the autocorrelated processes have a beta distribution with mean 0.5 and standard deviation of 0.2 ; the standard deviation of the innovations, including measurement errors, have an inverse-gamma distribution with mean 0.1 and standard deviation of $2 .{ }^{35}$ The priors for the parameters of the monetary policy reaction function are based on the Taylor rule, while the parameters of the fiscal policy rule are consistent with a passive fiscal regime. Based on Hall (1988) and Ravina (2011), the inverse intertemporal elasticity of substitution of consumption, $\sigma$, has a gamma distribution with mean 2 and a fairly large standard deviation of 0.6 , while the degree of habit persistence has a beta prior with mean 0.35. Turning to price and wage setting, the Rotemberg adjustment costs determine the parameters $\xi_{p}$ and $\xi_{w}$, interpretable as the probability of not resetting prices and wages in a Calvo setup. The prior mean implies an average duration of about one-half a year. As shown in the appendix, these parameters determine both the slope of the wage and price Phillips curve, and, also, the rate at which agents discount the future when making price and wage decisions - see also Preston (2005). For this reason, these parameters can be identified separately from the sources of real rigidity. Therefore, we estimate $\kappa$, the slope of the price Phillips curve, applying a beta prior distribution with mean 0.3 and standard deviation of 0.15 . The parameters capturing price and wage indexation, $\iota_{p}$ and $\iota_{w}$, have means of 0.5. Following Slobodyan and Wouters (2012a), the constant-gain coefficient has a gamma distribution with mean 0.035 and standard deviation of 0.03 .

Posterior Distributions. Tables 1 and 2 also show the mean, the mode and 95 percentiles of the posterior distribution of the parameters. Overall, the data are informative.

\footnotetext{
${ }^{32}$ This is the mean over the sample from the monthly statement of the public debt of the US from the Treasury Department.

${ }^{33}$ Because the counterfactuals consider substantially different debt burdens, a concern might be that high steady-state real interest rates overstate any identified effects. For this reason the appendix reports the results for an estimated model with $\beta=0.995$, which is consistent with an average term premium (defined as the difference between the average interest rate paid on debt and the three-month Tbill) of about $2 \%$ over the Great Moderation: the results are very close to our baseline model. Note, however, that higher debt burdens might reasonably be thought to be associated with higher equilibrium real interest rates, leading to the use of $\beta=0.99$ as the baseline value.

${ }^{34}$ This value is chosen to respect the steady-state link between debt, surplus and taxes.

${ }^{35}$ These are the last four standard deviations in Table 2.
} 
The shocks have lower persistence than usually found in estimated DSGE models. ${ }^{36}$ This reflects the role of learning in soaking up low-frequency variation in the data. The estimated intertemporal elasticity of substitution, $\sigma^{-1}$, is remarkably low, roughly between 0.1 and 0.2. The price and wage stickiness parameters, $\xi_{w}$ and $\xi_{p}$, are both consistent with price duration of over one year in terms of a Calvo model. In addition, the estimated slope of the Phillips curve is very flat, implying a high degree of real rigidity. The learning gain $\bar{g}$ is precisely estimated between 0.034 and 0.045: a short-term forecast error of $1 \%$ leads to a 4 basis point revision in the long-term drift. To interpret further, the gain implies an observation that is 10 -years old receives a weight of about $20 \%$. The monetary policy rule displays a response to inflation and the output gap that is not too different from the priors, save a high degree of interest smoothing. The tax rule also has considerable inertia. The price markup $\Phi_{p}=\theta_{p} /\left(\theta_{p}-1\right)$, which identifies the degree of preference non-separability in steady state, is high relative to the prior, while the habit parameter is close to its prior.

Stability. Statistical inference requires estimates to satisfy expectations stability, which ensures the true data-generating process is stationary. The appendix provides further results on expectational stability, which verify the implications of the Proposition for the empirical model, and show the dependency of these conditions on various features of the model specification. For example, a low intertemporal elasticity of substitution enhances the destabilizing role of wealth effects on consumption, while a high degree of price rigidity promotes stability. We also provide results for constant-gain and least-square learning when agents learn about all parameters in their vector auto-regression model, rather than just means.

\section{Fiscal Policy and the Transmission of Shocks}

The remaining sections of the paper explore implications of the model. Focus is given to fiscal policy, and the challenges that high-debt economies pose for the conduct of monetary policy, and the goal of price stability. The discussion develops in three steps. First, we use impulse response functions to demonstrate model dynamics under learning are fundamentally different to those under rational expectations. Second, armed with this understanding, we study how identified shocks explain the evolution of expectations and concomitant wealth effects on aggregate demand. Third, we generate counterfactual predictions to understand the interactions of monetary and fiscal policy.

\subsection{A Useful Decomposition}

To understand the mechanisms of the model, we express perceived wealth in terms of a set of forecast errors, defined as the difference between the subjective beliefs of agents and model-consistent expectations — the beliefs of a hypothetical agent who knows the true data-generating process under learning. By construction, the model is Ricardian under full information, so model-consistent expectations imply zero net wealth effects in every period. As for the endowment economy, the net wealth component of consumption demand is

$$
n_{w, t}=\left(\beta^{-1}-1\right) \times\left\{\left(\tilde{b}_{t-1}^{m}-\delta \hat{\pi}_{t}+\delta \beta \rho \hat{P}_{t}^{m}\right)+\beta \hat{E}_{t} \sum_{T=t}^{\infty} \beta^{T-t}\left[\delta\left(\hat{R}_{T+1}^{m}-\hat{\pi}_{T+1}\right)-\tilde{\tau}_{T}\right]\right\} .
$$

\footnotetext{
${ }^{36}$ See for example Smets and Wouters (2007), Justiniano, Primiceri and Tambalotti (2010), and Del Negro, Giannoni and Shorfiede (2014).
} 
Adding and subtracting model-consistent expectations for each term in this expression, and some algebra found in the appendix, provides

$$
\begin{aligned}
n_{w, t}= & \beta \delta\left[\sum_{T=t}^{\infty} \beta^{T-t}\left(\hat{E}_{t} r_{T+1}-\tilde{E}_{t} r_{T+1}\right)-\tilde{E}_{t} \sum_{T=t}^{\infty} \beta^{T-t}\left(\hat{R}_{T+1}^{m}-\hat{R}_{T}\right)\right] \\
& -\beta \sum_{T=t}^{\infty} \beta^{T-t}\left(\hat{E}_{t} \tilde{\tau}_{T}-\tilde{E}_{t} \tilde{\tau}_{T}\right)
\end{aligned}
$$

where $r_{t}=\hat{R}_{t}-E_{t} \hat{\pi}_{t+1}$ is the ex-ante short-term real interest rate and $\tilde{E}_{t}$ denotes modelconsistent expectations. Wealth effects emerge from three sources of forecast error. The first term measures the difference in expectations of the present discounted value of the short-term real rate; the second term defines the negative of the present discounted value of excess returns from holding long-term bonds using model-consistent expectations (note that expected returns from holding long- and short-term bonds are equalized via arbitrage only under subjective beliefs); and, finally, the third term is the negative of the difference in expected taxes.

The decomposition shows a lower expected path of taxes, or a higher expected path for the real rate, relative to model-consistent expectations, produces positive wealth effects. Both these terms capture the impact of beliefs on the perceived present discounted value of taxes. Higher expected real rates, imply a lower present discounted value of taxes. In contrast, changes in expected returns have the opposite effects on net wealth: bond prices that are too low relative to a model-consistent valuation lead to negative net wealth effects. Positive expected excess returns under model consistent expectations arise because the true data-generating process implies a predictable decline of long-term interest rates to steady state.

This difference between subjective and model-consistent beliefs highlight a fundamental property of the expectations formation process. Model-consistent expectations satisfy mean reversion as the true data-generating process is stationary with a mean corresponding to the rational expectations equilibrium. In contrast, because agents must infer the long-run conditional expectation of each variable, shifting assessments of the conditional mean lead to revision of the entire anticipated path of a given variable, leading them to systematically over predict the consequences of surprise increases in macroeconomic time series, and underpredict falls. This property of beliefs in infinite-horizon decision problems is central to model dynamics, and renders perspicuous the earlier claim, based on Eusepi and Preston (2011), that drifts in beliefs about the long-run mean generate the most important quantitative implications.

\subsection{Impulse and Propagation Mechanisms}

This section studies how different shocks drive wealth effects from holdings of the public debt. The empirical model defies analytical treatment. The effects of different disturbances on perceived wealth will, in general, depend on a range of model features. Econometric inference identifies the consequences of different shocks for perceived wealth effects. For brevity we focus on a monetary shock and a price markup shock, leaving all other impulse responses to the appendix. 
Price markup shock. Figure 1 illustrates the mean impulse responses to a price markup shock in our baseline economy (solid lines), and also in an otherwise identical economy, but with an average debt-to-output ratio of $200 \%$ (dashed lines). The high-debt scenario informs subsequent analysis of the model. Beliefs take rational expectations equilibrium values at the time of the disturbance. Consider the top four panels. A positive supply shock in a low-debt economy generates higher inflation, while the output gap declines in response to a steeper real interest rate path. This is the standard transmission mechanism of monetary policy in a Ricardian economy. Counterbalancing the restraining influence of higher real interest rates is a positive wealth effect on consumption demand. This additional source of demand prolongs the period of higher interest rates, leading to a protracted period of weak demand.

The final three panels identify the source of wealth effects using the above decomposition. Agents expect lower taxes and a higher path for the real interest rate relative to modelconsistent expectations. As the real rate increases and taxes decline in response to the shock, agents revise their long-run assessment of these variables. For example, the top two panels show how inflation and nominal interest-rate beliefs respond to the shock - agents expect a permanent increase in inflation and interest rates. In the case of taxes, beliefs are revised downwards, leading to a permanently lower anticipated tax burden. In contrast, model-consistent expectations correctly predict mean reversion in these economic variables. Muting these two positive contributions to net wealth, is a smaller negative contribution from expected excess returns. The steeper path for the nominal rate causes bond prices to be low relative to the model-consistent valuation of debt.

Tax expectations play a dominant role in generating positive wealth effects. Three factors determine the level of taxes. Higher inflation and lower bond prices (higher expected nominal rates) both lower the market value of outstanding debt in real terms, and, therefore, lower taxes directly through the tax policy rule. Counterbalancing this, from the flow budget constraint of the government, higher expected nominal interest rates lead to more debt issuance and therefore higher taxes. While generally the net effects depend on the parameters characterizing fiscal policy, the first two components dominate in response to a markup shock.

The wealth effects are small in an low-debt economy but they significantly alter the transmission mechanism of the shock in high-debt economies. Here the mean response of the output gap switches sign because of positive wealth effects. While the mechanics of adjustment are the same, large wealth effects from projected declines in taxes, and later, rising projected real rates, offset the typical decline in aggregate demand in response to the negative supply shock. Perceived wealth effects undermine the stabilizing influence of higher interest rates operating through intertemporal substitution motives. In high-debt economies shocks have larger and more persistent effects.

Monetary policy shock. Figure 2 shows the mean impulse response to a contractionary monetary policy shock. Both inflation and the output gap fall in response to the shock. As with the price markup shock, the substitution effects reducing aggregate demand are partially off-set by positive wealth effects. These are induced by only one out of the three components of net wealth: the steeper expected path of the real rate, which leads to a fall in the present discounted value of taxes. Indeed, low inflation and high-debt issuance associated with the nominal interest rate increase, tend to raise taxes, and, concomitantly, tax beliefs, over the 
medium term. ${ }^{37}$ This produces negative effects on consumption demand since agents now over-estimate the present discounted value of taxes. Similarly, the steep increase in the path of the nominal interest rate produces positive expected excess returns to long-term bonds, with negative impact on consumption demand. In a high-debt economy the re-weighting of substitution and wealth effects mutes the short-term drop in the output gap. The effects are, however, more persistent than in a low-debt economy.

In summary, wealth effects generally have opposite effects on aggregate demand when compared to the standard intertemporal substitution channel of monetary policy. Imperfect knowledge fundamentally alters impulse and propagation mechanisms. Section 7 shows this renders monetary policy less effective in stabilizing high-debt economies.

\subsection{Expectations and Wealth Effects}

This section details how the estimated model accounts for the data. Figure 3 shows selected macroeconomic variables over the sample period. The two top panels display the evolution of inflation and interest rates, and, for each of these variables, the five-to-ten-year-ahead expectations from both survey forecasts (red diamonds) and model-implied forecasts (black solid line). ${ }^{38}$ Long-term inflation expectations drift up to about $7 \%$ in the late 1970 s, and gradually return to the true unconditional mean of $2 \%$ in the late 1990 s. Similarly, long-term interest-rate forecasts exhibit considerable drift over the sample. Revisions in estimated drifts $\hat{\omega}_{t}^{\pi}$ and $\hat{\omega}_{t}^{i}$ (blue solid line) explain these patterns in long-term expectations. The learning model accounts for the Great Inflation without reliance on an exogenously specified inflation target disturbance, as Cogley and Sbordone (2008) and Del Negro, Giannoni, and Schorfheide (2015), among others, assume.

The impulse response functions anticipate small wealth effects on aggregate dynamics. The middle-left panel illustrates the evolution of both consumption less wealth, $c_{t}-n_{w, t}$, and net wealth, $n_{w, t}$. Non-Ricardian effects play only a minor role in determining the evolution of output and inflation, including the Great Inflation. This is not to say imperfect knowledge is unimportant in explaining the data - drifting beliefs are central to inflation and interestrate dynamics. However, imperfect knowledge of the fiscal regime induces non-Ricardian demand effects that are small.

The remaining panels in Figure 3 plot the components of net wealth (black solid line) as defined by the above decomposition and compares them with the overall level of net wealth, $n_{w, t}$ (red solid line). Expected taxes play a dominant role in explaining movements in wealth. Their present discounted value relative to model-consistent expectations is positive until the early 1980s, when taxes were under predicted, and then turns negative until the mid-2000s. While we do not have supporting survey evidence, Laubach (2009) discusses the evolution of five-years-ahead deficit and debt projections from the Congressional Budget Office. Consistent with our model, that paper shows large under-predictions in the 1970s, and over-predictions in the early 1990s.

Net wealth from movements in the real rate (relative to model-consistent expectations) mimic fluctuations in the policy rate. Expansionary policies in place during the 1970s created

\footnotetext{
${ }^{37}$ Even though taxes initially dip, debt issuance increases, raising beliefs about long-run debt and, therefore, long-run taxes.

${ }^{38}$ The estimated observation errors in Table 2 reveal the model does a good job fitting the survey data.
} 
negative wealth effects that were reversed during the Volcker disinflation. The last panel on the right shows positive excess returns from holding long-term bonds throughout the sample, yielding negative wealth effects - interest rates, and interest-rate expectations, were generally above their unconditional mean. For example, in 1980, agents expected the short-term rate to remain around 9\%: the equilibrium bond-price reflected those views. However, model-consistent bond-price expectations imply current bond prices are too low, as short-term rates are expected to revert to their unconditional mean of $4 \%$, yielding positive expected excess returns. This partially offsetting behavior of the three components of wealth is an additional reason for its small role in affecting consumption demand.

Figure 4 shows the historical contribution of each of three types of shocks (demand, supply and monetary shocks) to the variables described above. We interpret supply shocks as the combined effects of the three supply-side disturbances: price markup, wage markup and technology shocks. For reasons the endowment economy analysis explicates, tax shocks satisfy Ricardian Equivalence and explain no variation in the plotted series. The contribution of estimated initial conditions is also shown. To assist interpretation, the shock decomposition uses an annual frequency. Broadly, the historical account of the data agrees with the narrative found in Smets and Wouters (2007). Excessively loose monetary policy and large adverse supply shocks account for much of the rise in inflation and short-term interest rates during the 1970s. Short-term forecast errors, driven primarily by surprise monetary and supply shocks, led to consistent rises in long-term beliefs about inflation and interest rates. While supply shocks drive the recession in 1974, tight monetary policy during the Volcker disinflation led to a large drop in the output gap in the early 1980s. During the mid 1990s the increase in output and further stabilization in inflation expectations is driven by favorable supply shocks. Finally, net wealth is positive over the 1970s, initially reflecting the predominance of positive supply shocks and later tight monetary policy (recall the impulse response functions discussed earlier). From the mid 1980s, positive demand and negative supply shocks generate falls in perceived net wealth, reducing aggregate demand. ${ }^{39}$

\section{Wealth Effects in a High-Debt Economy}

The model predicts that wealth effects are a relatively unimportant source of demand in the historical sample. Substitution effects dominate, and Ricardian equivalence is a reasonable approximation to the data. However, in many countries, including the United States, the stance of fiscal policy has changed radically during the recent financial crises, raising the question of whether one ought always to expect fiscal policy to place few constraints on the conduct of monetary policy. Indeed, the impulse response functions show high debt fundamentally alters impulse and propagation mechanisms of the imperfect knowledge economy. Might fiscal policy present challenges to central banks committed to price stability?

To assess a substantial change in the fiscal position of the US economy, we conduct counterfactual exercises which assume the economy is subject to the same sequences of disturbances identified in estimation. ${ }^{40}$ Figure 5 plots "volatility frontiers" corresponding

\footnotetext{
${ }^{39}$ Similarly to an expansionary monetary shock, a positive spending shock produces negative wealth effects. See the impulse responses in the appendix.

${ }^{40}$ The counterfactuals assume beliefs are characterized by the same constant gain implied by the posterior distribution. Furthermore, initial beliefs, part of the unobserved state inferred in estimation, are scaled
} 
to different assumptions about the size and maturity of government debt. The left panels show the relationship between the average duration of debt and the standard deviation of inflation and the output gap in an economy with a debt-to-output ratio of $120 \%$ (Italy, for example). The right panel describes an economy with a $200 \%$ debt to-output-ratio (Japan, for example). Consistent with theoretical results, intermediate maturities of debt lead to substantial volatility in both the output gap and inflation relative to our baseline economy (red line). Moreover, high-debt economies create more volatility in median outcomes (solid black lines), and higher uncertainty, with widening 95 percent posterior probability outcomes. The volatility of the output gap rises more than inflation, reflecting a flat goods price Phillips curve. Despite policy always satisfying the requirements for expectations stability, learning fundamentally alters dynamic properties of the model.

Figure 6 shows the predicted evolution of key variables under two counterfactual debt structures. The left panel shows an economy with $200 \%$ debt-to-output ratio and a maturity of debt corresponding to the baseline calibration. In this economy the output gap moves substantially. So do interest-rate expectations. The effects are less dramatic for inflation, again reflecting the flat Phillips curve. The 1974 recession, driven by positive supply shocks, disappears in the counterfactual: recall the impulse responses show a high-debt economy reverses the output gap response to a price markup shock. Negative wealth effects in the mid-1980s drive the policy rate below the zero lower bound. The economy experiences very low inflation, and deflation for some realizations. Inflation would be substantially lower if the model took account of the zero lower bound constraint on the nominal interest rate, which the simulations ignore. The economy again encounters the zero lower bound in the mid-2000s - a high-debt economy would have vindicated deflation fears of contemporary economic commentators. A monetary policy framework which successfully stabilizes inflation, inflation expectations and economic activity, loses effectiveness when the fiscal regime shifts from lowto high-debt levels. This policy ineffectiveness arises even though the fiscal policy regime adjusts taxes to back outstanding debt.

Finally, the right panel in Figure 6 shows the same counterfactual but with an average debt duration of 14 years. The role of wealth effects decreases substantially in this economy. Despite the high-debt burden, monetary policy retains its power to control inflation. This simulation emphasizes that the choice of the maturity of debt can have important implications for monetary policy.

Robustness of the Gain. The policy exercises above assume expectations formation to be invariant to the policy regime. However a constant gain chosen in some optimal way, should respond to a change in policy. For example a fiscal regime leading to higher short-term volatility could lead to a lower gain, as agents revise their assessment of the signal-to-noise ratio. Conversely, the gain could be updated upwards if higher volatility is associated with more volatile long-term fundamentals. While a treatment of the optimal gain is beyond the scope of this paper, the appendix shows a counterfactual where higher steady-state debt is associated with a lower gain $(\bar{g}=0.02)$ : this economy continues to display large fluctuations albeit a bit reduced from the baseline. ${ }^{41}$ In addition, drift movement occur at somewhat

appropriately: for example, if estimated initial long-run inflation beliefs are above steady state by 1 percent, then same percentage deviation is maintained in the counterfactual.

${ }^{41}$ Marcet and Nicolini (2003) introduce a framework where the constant gain responds to a change in policy regime. For an alternative approach where near-rational expectations are not invariant to the policy 
lower frequencies: for example the zero lower bound is reached later with a lower constant gain.

\section{Discussion}

Some implications of the empirical results are now discussed. We also relate the theory to other literature that argues the importance of debt to a proper understanding of inflation.

Policy implications and inference. The counterfactual experiments using the empirical model demonstrate the conduct of fiscal policy was relevant to the success of the Volcker Disinflation and the subsequent Great Moderation. Ricardian equivalence provides a reasonable approximation of low-debt economies. If fiscal policy in the US had been characterized by higher average levels of debt, then volatility would have been higher than observed. Hence good fiscal policy also appears to be central to the stability of the 1980s and 1990s. The results have relevance for contemporary policy debate, given substantial increases in debt-to-GDP ratios in many countries.

Outside of the domain of dynamic stochastic general equilibrium analyses, the results have implications for empirical analysis of inflation. For example, in general vector-autoregression models do not a priori impose rational expectations or Ricardian equivalence. Identified fiscal disturbances potentially reflect the mechanisms of this paper. Future work should attempt to detect these influences.

Policy design and adaptive learning. These results build on a now large literature on learning dynamics and inflation control. Bullard and Mitra (2002), Evans and Honkapohja (2003) and Preston $(2005,2006)$ consider the stability properties of interest-rate rules in a New Keynesian model in which one-period-ahead expectations matter and there is no public debt. ${ }^{42}$ In models with one-period debt Evans and Honkapohja (2007) and Eusepi and Preston (2012) explore the interactions of fiscal and monetary policy, characterizing learning analogues to the seminal insights of Leeper's (1991) rational expectations analysis. A specific implication is the standard account of monetary policy, with active monetary policy and passive fiscal policy, is shown to be always stable under learning, regardless of the size of debt if interest rates are adjusted in response to current inflation. ${ }^{43}$ The present paper advances these contributions, demonstrating that the maturity structure itself is a critical determinant of inflation control in models of imperfect knowledge.

The Fiscal Theory of the Price Level. The fiscal theory of the price level - see Leeper (1991), Sims (1994), Woodford (1996) and Cochrane (2001) — asserts a distinct mechanism by which debt determines inflation. In contrast to the unpleasant monetarist arithmetic of Sargent and Wallace (1981), the connection between debt and inflation is not determined causally by printing money - though money balances might adjust because of equilibrium considerations. Rather, the theory contends that certain choices of fiscal policy can render future structural surpluses insufficiently responsive to outstanding debt. The only way intertemporal solvency of government accounts can be restored is through adjustments in the price level to ensure consistency between the real value of current outstanding debt

regime see Adam and Woodford (2012).

${ }^{42}$ Preston (2005) and Preston (2006) use a model of anticipated utility employed here.

${ }^{43}$ Eusepi and Preston (2012) shows that when monetary policy rules respond to inflation expectations instability can occur in more heavily indebted economies. See also the appendix for a related result. 
and the real present discounted value of structural surpluses. Here fiscal policy determines inflation, while monetary policy maintains the value of the public debt. This theory predicts that debt has monetary consequences.

A striking difference of our work is that the fiscal regime affects inflation dynamics even when monetary policy satisfies the Taylor principle and taxes respond sufficiently to debt to guarantee intertemporal solvency. This property has much in common with regime switching models of policy. Starting with Davig and Leeper (2006) there has been a concerted effort to understand the consequence of shifts in policy regime for macroeconomic dynamics. The central idea is that while there are periods in which policy is conducted according to conventional wisdom, with monetary policy providing a nominal anchor, there may also be periods in which fiscal policy determines the price level, with monetary policy stabilizing the level of the public debt. To the extent that there is non-zero probability weight on this second regime, debt will have monetary consequences, even during periods when policy is conducted according to the first regime.

Sims (2011b), Bianchi and Ilut (2017) and Bianchi and Melosi (2017) invoke this theory to explain the surge in inflation in the 1970s, when monetary policy has been characterized as passive. The large role of fiscal policy found in these studies contrast with our results. We offer two observations. First, these papers allow explicitly for an active fiscal regime in the 1970s, while fiscal policy is passive throughout the sample in this paper. They capture low-frequency movements in inflation using this regime, rather than drift in inflation and interest-rate beliefs. Second, the inflationary consequences of wealth effects from fiscal policy decline with lower levels of debt in our framework, while this is not true in the fiscal theory of the price level. High-debt economies are inherently more difficult to control.

Also related to our paper is Sims (2011a). In contrast to our analysis, Sims proposes that agents make model consistent forecasts except for inflation. Conditional expectations of inflation are assumed to depend on debt. This is a reduced-form description of beliefs that would arise in a formal model of policy regime change discussed above. Like our paper, it does not require explicit characterization of alternative regimes. Unlike our paper, it is somewhat less general, restricting the possible influence of alternative regimes to inflation expectations alone. ${ }^{44}$ Nonetheless, Sims demonstrates, consistent with the analysis of Eusepi and Preston (2012) and this paper, that tighter monetary policy can lead to bursts of future inflation in the medium term - even when monetary and fiscal policy have conventional assignments. Sims (2011a) refers to this as "stepping on a rake" — see also Sims (2011b).

\section{Conclusions}

This paper provides fiscal foundations of inflation based on imperfect knowledge and learning. It defines an economic environment where holdings of the public debt are perceived as net wealth, giving scope for the scale and composition of debt to be relevant to inflation dynamics. Both characteristics of debt place constraints on monetary control. High debt and moderate maturity economies require more aggressive monetary policy to deliver expectations stability.

\footnotetext{
${ }^{44}$ As shown in section 6.2, in our framework the relation between debt and expected inflation depends on the specific shock.
} 
An estimated version of the model reveals perceived net wealth does not play a key role in the run-up of inflation in the 1970s, or in the subsequent period of economic stability. This reflects the relatively low levels of public debt through the entire period. The analysis shows that had the US experienced a fiscal burden similar to current levels in Japan, the Great Moderation would not have occurred, and monetary policy would have been constrained at the zero lower bound for prolonged periods. Fiscal policy matters for inflation control. 


\section{REFERENCES}

Adam, K., J. Beutel, and A. Marcet (2013): "Stock Price Booms and Expected Capital Gains," unpublished, University of Mannheim.

Adam, K., And M. Woodford (2012): "Robustly optimal monetary policy in a microfounded New Keynesian model," Journal of Monetary Economics, 59(5), 468-487.

Ascari, G., A. Florio, And A. GobBi (2017): "Controlling inflation with switching monetary and fiscal policies: expectations, fiscal guidance and timid regime changes," Research Discussion Papers 9/2017, Bank of Finland.

Beck-Friss, P., And T. Willems (2017): "Dissecting fiscal multipliers under the fiscal theory of the price level," European Economic Review, 95(C), 62-83.

Benhabib, J., S. Schmitt-Grohe, and M. Uribe (2001): "Monetary Policy and Multiple Equilibria," American Economic Review, 91(1), 167-186.

Bianchi, F., And C. Ilut (2017): "Monetary/Fiscal Policy Mix and Agent's Beliefs," Review of Economic Dynamics, 26, 113-139.

Bianchi, F., And L. Melosi (2017): "Escaping the Great Recession," American Economic Review, 17(4), 1030-58.

Bullard, J., And K. Mitra (2002): "Learning About Monetary Policy Rules," Journal of Monetary Economics, 49(6), 1105-1129.

Clarida, R., J. Gali, and M. Gertler (1999): "The Science of Monetary Policy: A New Keynesian Perspective," Journal of Economic Literature, 37, 1661-1707.

(2000): "Monetary Policy Rules and Macroeconomic Stability: Evidence and Some Theory," Quarterly Journal of Economics, 115, 147-180.

Cochrane, J. H. (2001): "Long term debt and optimal policy in the fiscal theory of the price level," Econometrica, (69), 69-116.

- (2011): "Determinacy and Identification with Taylor Rules," Journal of Political Economy, 119(3), $565-615$.

Cogley, T., And A. M. Sbordone (2008): "Trend Inflation, Indexation, and Inflation Persistence in the New Keynesian Phillips Curve," American Economic Review, 98(5), 2101-26.

Crump, R., S. Eusepi, and E. Moench (2015): "The Term Structure of Expectations and Bond Yields," unpublished, Federal Reserve Bank of New York.

Davig, T., And E. Leeper (2006): "Fluctuating Macro Policies and the Fiscal Theory," in NBER Macroeconomics Annual, ed. by D. Acemoglu, K. Rogoff, and M. Woodford, vol. 21. 
Del Negro, M., M. P. Giannoni, and F. Schorfheide (2015): "Inflation in the Great Recession and New Keynesian Models," American Economic Journal: Macroeconomics, $7(1), 168-96$.

Eusepi, S., M. Giannoni, and B. Preston (2015): "The Limits of Monetary Policy with Long-term Drift in Expectations," unpublished, The University of Melbourne.

Eusepi, S., And B. Preston (2011): "Expectations, Learning and Business Cycle Fluctuations," American Economic Review, 101(6), 2844-2872.

(2012): "Debt, Policy Uncertainty and Expectations Stabilization," Journal of the European Economics Association, 10(4), 860-886.

(2016): "The Science of Monetary Policy: An Imperfect Knowledge Perspective," forthcoming Journal of Economic Literature, The University of Melbourne.

Evans, G. W., And S. HonkApohJA (2001): Learning and Expectations in Economics. Princeton, Princeton University Press.

(2003): "Expectations and the Stability Problem for Optimal Monetary Policies," Review of Economic Studies, 70(4), 807-824.

(2007): "Policy Interaction, Learning and the Fiscal Theory of Prices," Macroeconomic Dynamics, 11, 665-690.

Evans, G. W., S. Honkapohja, and K. Mitra (2012): "Does Ricardian Equivalence Hold When Expectations Are Not Rational?," Journal of Money, Credit and Banking, 44(7), 1259-1283.

Fernandez-Villaverde, J., P. Guerron-Quintana, and J. F. Rubio-Ramirez (2010): "Fortune or Virtue: Time-Variant Volatilities Versus Parameter Drifting," University of Pennsylvannia and Duke University.

Giannoni, M., and M. Woodford (2004): "Optimal Inflation-Targeting Rules," in The Inflation-Targeting Debate, NBER Chapters. National Bureau of Economic Research, Inc.

Hall, R. E. (1988): "Intertemporal Substitution in Consumption," Journal of Political Economy, 96.

Justiniano, A., And G. E. Primiceri (2008): "The Time Varying Volatility of Macroeconomic Fluctuations," American Economic Review, 98, 604-641.

Kozicki, S., And P. A. Tinsley (2012): "Effective Use of Survey Information in Estimating the Evolution of Expected Inflation," Journal of Money, Credit and Banking, 44(1), $145-169$.

Kreps, D. (1998): "Anticipated Utility and Dynamic Choice," in Frontiers of Research in Economic Theory, ed. by D. Jacobs, E. Kalai, and M. Kamien, pp. 242-274. Cambridge: Cambridge University Press. 
Laubach, T. (2009): "New Evidence on the Interest Rate Effects of Budget Deficits and Debt," Journal of The European Economic Association, 7(4), 858-885.

Lubik, T. A., And F. Schorfheide (2004): "Testing for Indeterminacy: An Application to U.S. Monetary Policy," American Economic Review, 94, 190-217.

Marcet, A., And J. P. Nicolini (2003): "Recurrent Hyperinflations and Learning," American Economic Review, 93(5), 1476-1498.

Marcet, A., and T. J. Sargent (1989): "Convergence of Least-Squares Learning in Environments with Hidden State Variables and Private Information," Journal of Political Economy, pp. 1306-1322.

Milani, F. (2007): "Expectations, Learning and Macroeconomic Persistence," Journal of Monetary Economics, 54, 2065-2082.

Orphanides, A., and J. C. Williams (2005): "Imperfect Knowledge, Inflation Expectations, and Monetary Policy," in The Inflation Targeting Debate, ed. by B. S. Bernanke, and M. Woodford. University of Chicago Press.

Preston, B. (2005): "Learning About Monetary Policy Rules when Long-Horizon Expectations Matter," International Journal of Central Banking, 1(2), 81-126.

(2006): "Adaptive Learning, Forecast-Based Instrument Rules and Monetary Policy," Journal of Monetary Economics, 53, 507-535.

Primiceri, G. E. (2005): "Time Varying Structural Vector Autoreggressions and Monetary Policy," Review of Economic Studies, 72, 821-852.

Ravina, E. (2011): "Habit Persistence and Keeping Up with the Joneses:Evidence from Micro Data," NYU Working Paper FIN-05-046, Columbia University.

Sargent, T., N. Williams, and T. Zha (2006): "Shocks and Government Beliefs: The Rise and Fall of American Inflation," American Economic Review, 96(4), 1193-1224.

Sargent, T. J. (1999): The Conquest of American Inflation. Princeton University Press.

Sargent, T. J., And N. Wallace (1981): "Some Unpleasant Monetary Arithmetic," Federal Reserve Bank of Minneapolis Quarterly Review, 5(3), 1-17.

Sims, C. A. (1994): "A Simple Model for the Determination of the Price Level and the Interaction of Monetary and Fiscal Policy," Economic Theory, 4, 381-399.

_ (2011a): "Model With Fiscal-Driven Inflation Expectations," unpublished, Princeton University.

(2011b): "Stepping on a rake: The role of fiscal policy in the inflation of the 1970s," European Economic Review, 55(1), 48-56. 
Sims, C. A., And T. Zha (2006): "Were there Regime Switches in U.S. Monetary Policy?" American Economic Review, 96, 54-81.

Sinha, A. (2016): "Learning and the Yield Curve," Journal of Money, Credit and Banking, $48(2-3), 513-547$.

Slobodyan, S., and R. Wouters (2012a): "Learning in a Medium-Scale DSGE Model with Expectations Based on Small Forecasting Models," American Economic Journal: Macroeconomics, 4(2), 65-101.

(2012b): "Learning in an estimated medium-scale DSGE model," Journal of Economic Dynamics and Control, 36(1), 26-46.

Woodford, M. (1996): "Control of the Public Debt: A Requirement for Price Stability," NBER Working Paper 5684.

University.

(1998): "Public Debt and the Price Level," unpublished manuscript, Columbia (2001): "Fiscal Requirements of Price Stability," Journal of Money, Credit and Banking, 33, 669-728.

(2003): Interest and Prices: Foundations of a Theory of Monetary Policy. Princeton University Press. 
10 Appendix: Proof of the Proposition

The local stability of the ODE in (23) is determined by the eigenvalues of the matrix

$$
T-I=\left[\begin{array}{cc}
\Gamma_{\pi}-1 & -\frac{\sigma}{\phi_{\pi}} \\
-\left(\beta^{-1}-(1-\rho) \phi_{\pi}\right) \delta \Gamma_{\pi}+\frac{(1-\rho) \beta \rho}{1-\beta \rho} \delta \phi_{\pi} & \left(\beta^{-1}-(1-\rho) \phi_{\pi}\right) \delta \frac{\sigma}{\phi_{\pi}}-1
\end{array}\right],
$$

where

$$
\Gamma_{\pi}=-\left(1-\sigma \delta\left(\beta^{-1}-1\right)\right) \frac{\beta-\phi_{\pi}^{-1}}{1-\beta}-\left(\frac{(1-\rho) \beta \rho}{1-\beta \rho}+\frac{\beta \rho^{2}}{1-\beta \rho}\right) .
$$

It is immediate to verify that the both eigenvalues are negative. The determinant of $T-I$ is $\left(1-\phi_{\pi}^{-1}\right) /(1-\beta)$ and it is positive under the assumed $\phi_{\pi}>1$. The trace is negative provided

$$
\phi_{\pi}>\left(1+(1-\beta)\left(1-\sigma \delta \times \frac{(1-\rho) \rho \beta}{1-\rho \beta}\right)\right)^{-1} .
$$




\begin{tabular}{llll|llcr}
\multicolumn{4}{c}{ Prior distribution } & \multicolumn{4}{c}{ Posterior distribution } \\
\cline { 2 - 7 } & Distr. & Mean & St. Dev. & Mode & Mean & 5 percent & 95 percent \\
\hline \hline$\sigma$ & Gamma & 2.000 & 0.600 & 6.922 & 7.147 & 5.642 & 8.748 \\
$b$ & Beta & 0.350 & 0.100 & 0.499 & 0.501 & 0.448 & 0.554 \\
$\xi_{w}$ & Beta & 0.500 & 0.050 & 0.757 & 0.743 & 0.652 & 0.814 \\
$\iota_{w}$ & Beta & 0.500 & 0.150 & 0.337 & 0.392 & 0.189 & 0.623 \\
$\xi_{p}$ & Beta & 0.500 & 0.050 & 0.755 & 0.738 & 0.674 & 0.798 \\
$\iota_{p}$ & Beta & 0.500 & 0.150 & 0.526 & 0.544 & 0.475 & 0.613 \\
$\Theta_{p}$ & Normal & 1.250 & 0.120 & 1.592 & 1.620 & 1.479 & 1.763 \\
$\kappa$ & Beta & 0.300 & 0.150 & 0.003 & 0.003 & 0.002 & 0.004 \\
$\phi_{\pi}$ & Normal & 1.500 & 0.150 & 1.522 & 1.623 & 1.490 & 1.767 \\
$\rho_{i}$ & Beta & 0.500 & 0.100 & 0.849 & 0.857 & 0.835 & 0.877 \\
$\phi_{x}$ & Normal & 0.120 & 0.050 & 0.077 & 0.094 & 0.069 & 0.131 \\
$\rho_{\tau}$ & Beta & 0.700 & 0.100 & 0.839 & 0.835 & 0.768 & 0.897 \\
$\phi_{\tau_{l}}$ & Gamma & 0.070 & 0.020 & 0.043 & 0.047 & 0.027 & 0.071 \\
$g$ & Gamma & 0.035 & 0.030 & 0.039 & 0.039 & 0.034 & 0.045 \\
\hline
\end{tabular}

Note: The posterior distribution is obtained using the Metropolis-Hastings algorithm.

Table 1: Prior and Posterior Distribution of Structural Parameters

\begin{tabular}{llll|lccc} 
& \multicolumn{3}{c|}{ Prior distribution } & \multicolumn{4}{c}{ Posterior distribution } \\
\cline { 2 - 7 } & Distr. & Mean & St. Dev. & Mode & Mean & 5 percent & 95 percent \\
\hline \hline$\rho_{\theta_{w}}$ & Beta & 0.500 & 0.200 & 0.891 & 0.870 & 0.791 & 0.921 \\
$\rho_{g}$ & Beta & 0.500 & 0.200 & 0.934 & 0.931 & 0.912 & 0.950 \\
$\rho_{\bar{\tau}}$ & Beta & 0.500 & 0.200 & 0.061 & 0.073 & 0.019 & 0.151 \\
$\rho_{a}$ & Beta & 0.500 & 0.200 & 0.865 & 0.855 & 0.821 & 0.882 \\
$\sigma_{\theta_{w}}$ & Inv.-Gamma & 0.100 & 2.000 & 0.162 & 0.186 & 0.141 & 0.253 \\
$\sigma_{\theta_{p}}$ & Inv.-Gamma & 0.100 & 2.000 & 0.201 & 0.201 & 0.180 & 0.224 \\
$\sigma_{g}$ & Inv.-Gamma & 0.100 & 2.000 & 0.510 & 0.526 & 0.438 & 0.623 \\
$\sigma_{m}$ & Inv.-Gamma & 0.100 & 2.000 & 0.195 & 0.197 & 0.179 & 0.218 \\
$\sigma_{\bar{\tau}}$ & Inv.-Gamma & 0.100 & 2.000 & 2.046 & 2.088 & 1.898 & 2.295 \\
$\sigma_{a}$ & Inv.-Gamma & 0.100 & 2.000 & 1.441 & 1.418 & 1.046 & 1.844 \\
$\sigma_{g \gamma}$ & Beta & 0.500 & 0.200 & 0.468 & 0.480 & 0.368 & 0.600 \\
$\sigma_{o, \pi^{S R}}$ & Inv.-Gamma & 0.100 & 2.000 & 0.179 & 0.184 & 0.161 & 0.208 \\
$\sigma_{o, R^{S R}}$ & Inv.-Gamma & 0.100 & 2.000 & 0.058 & 0.059 & 0.052 & 0.068 \\
$\sigma_{o, R^{L R}}$ & Inv.-Gamma & 0.100 & 2.000 & 0.047 & 0.057 & 0.030 & 0.092 \\
$\sigma_{o, \pi^{L R}}$ & Inv.-Gamma & 0.100 & 2.000 & 0.045 & 0.049 & 0.035 & 0.067 \\
\hline
\end{tabular}

Note: The posterior distribution is obtained using the Metropolis-Hastings algorithm.

Table 2: Prior and Posterior Distribution of Shock Processes 
Inflation; $\omega_{t}^{\pi}$

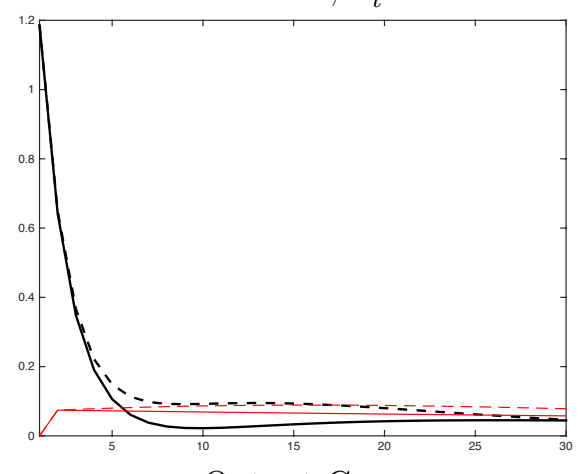

Output Gap

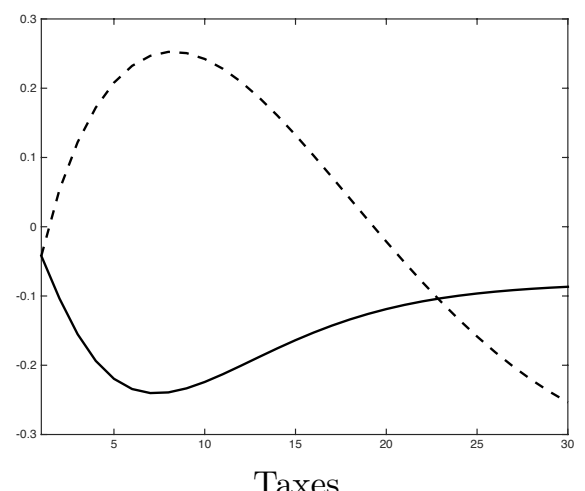

Taxes

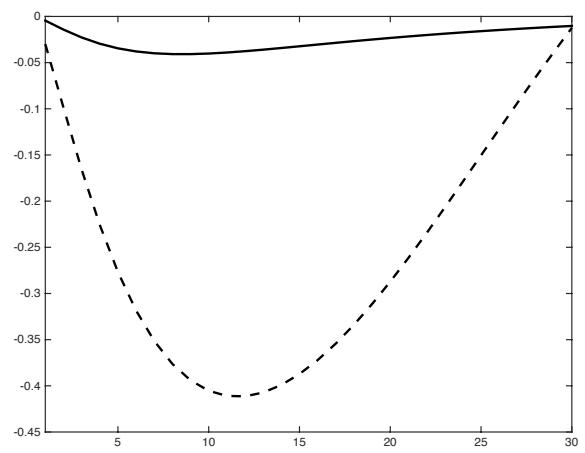

Net Wealth: Real rate

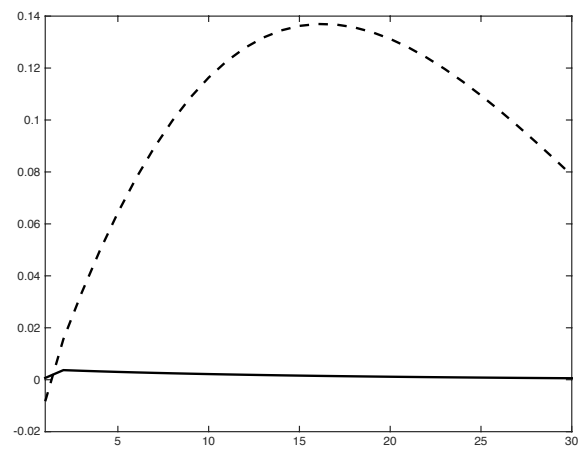

Interest Rate; $\omega_{t}^{i}$

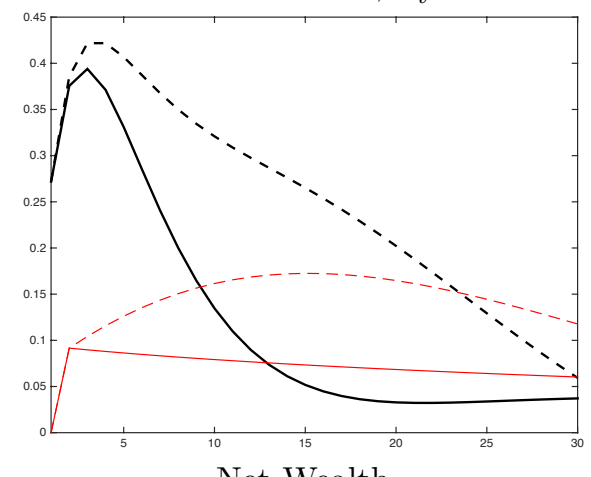

Net Wealth

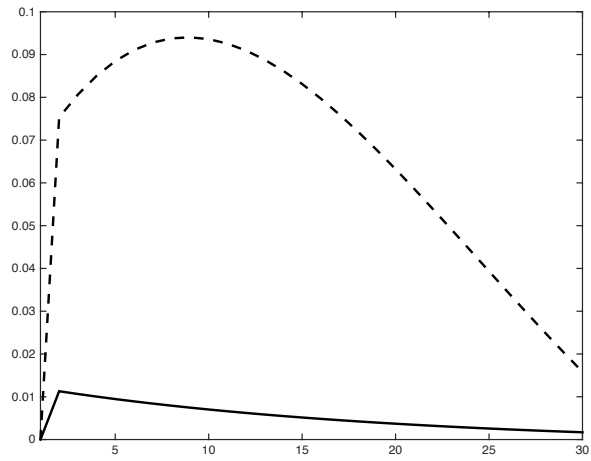

Net Wealth: Taxes

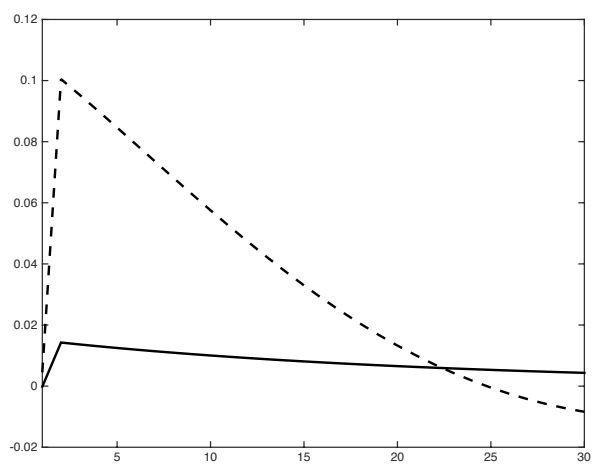

Net Wealth: Excess Return

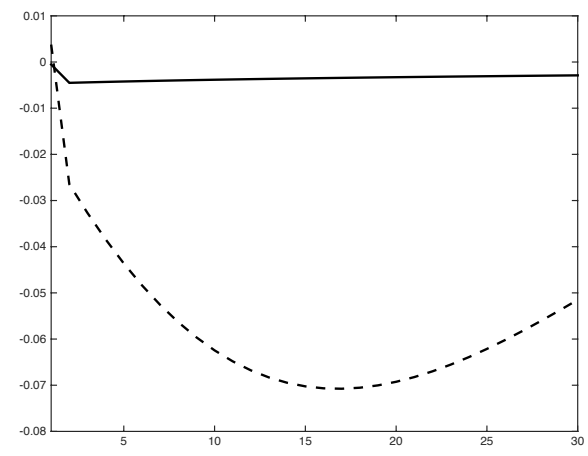

Figure 1: Mean Impulse Response to a Price Markup Shock

Solid lines denote the baseline economy with Debt-to-output ratio of 30\%. Dashed lines correspond to an economy with debt-to-output ratio of $200 \%$. Red lines measure inflation and interest rate estimated drifts. 


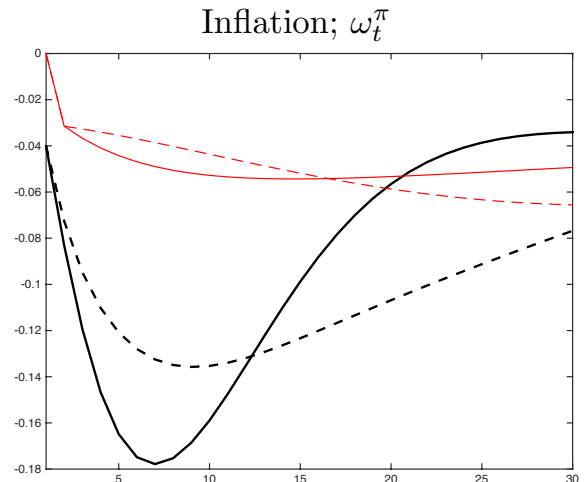

Output Gap

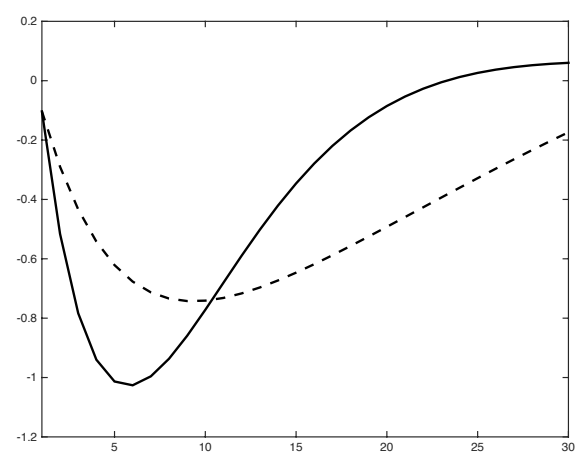

Taxes

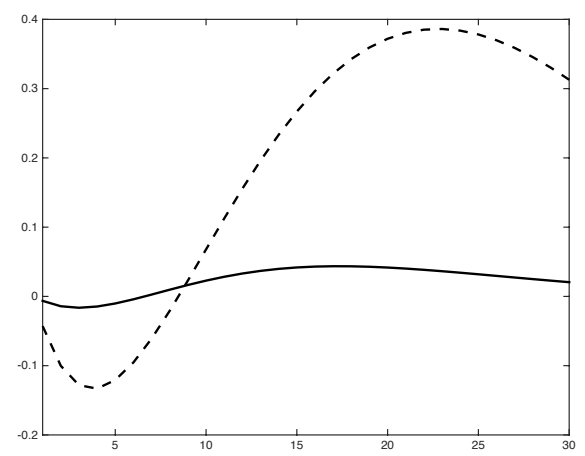

Net Wealth: Real rate

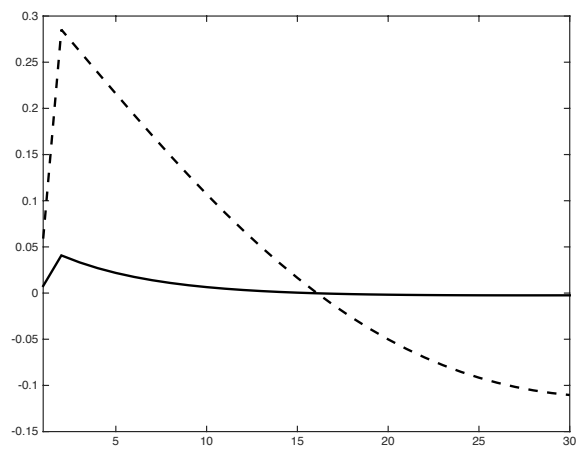

Interest Rate; $\omega_{t}^{i}$

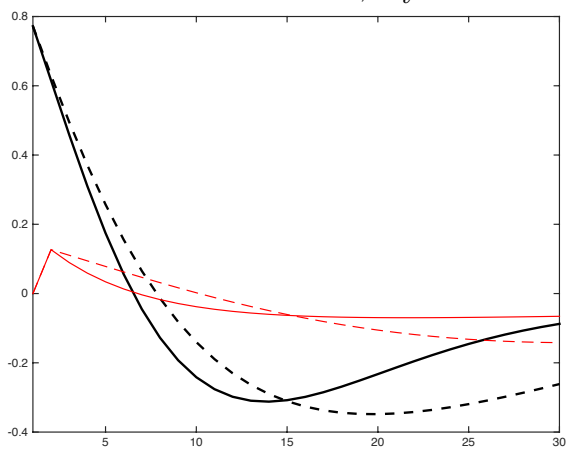

Net Wealth

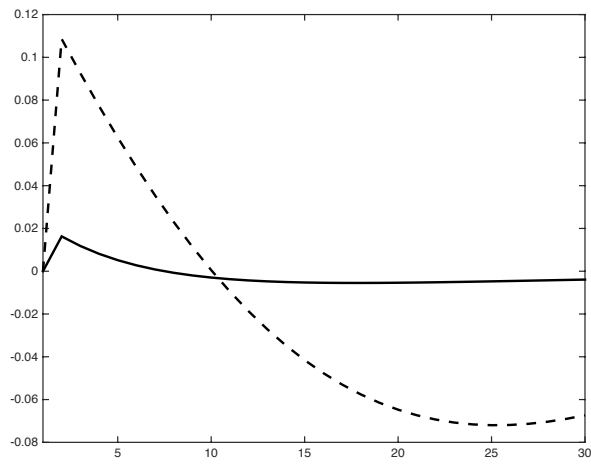

Net Wealth: Taxes

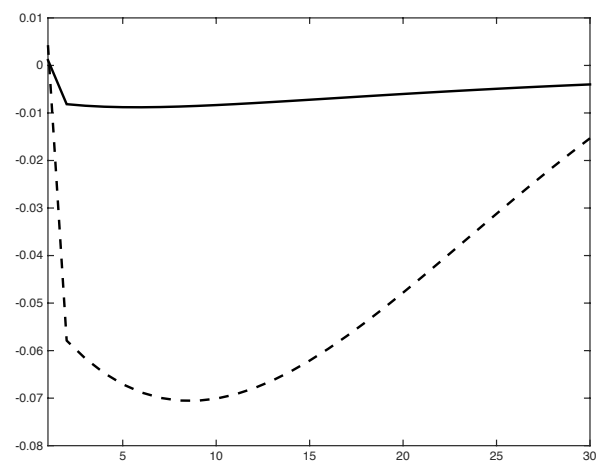

Net Wealth: Excess Return

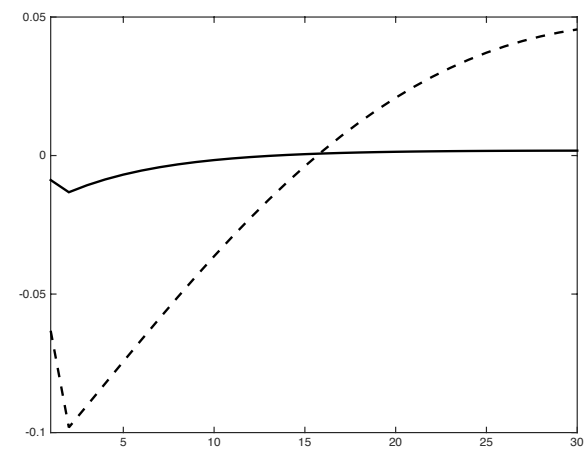

Figure 2: Mean Impulse Response to a Monetary Policy Shock

Solid lines denote the baseline economy with Debt-to-output ratio of 30\%. Dashed lines correspond to an economy with debt-to-output ratio of $200 \%$. Red lines measure inflation and interest rate estimated drifts. 


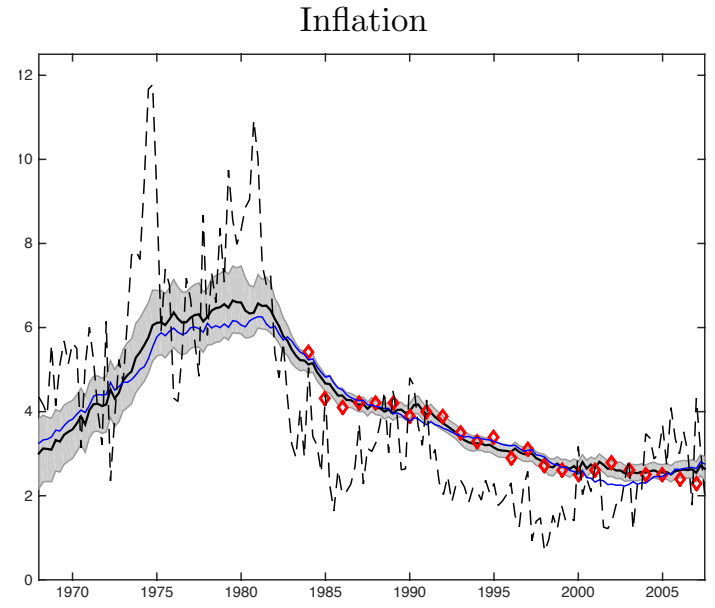

Consumption and Net Wealth

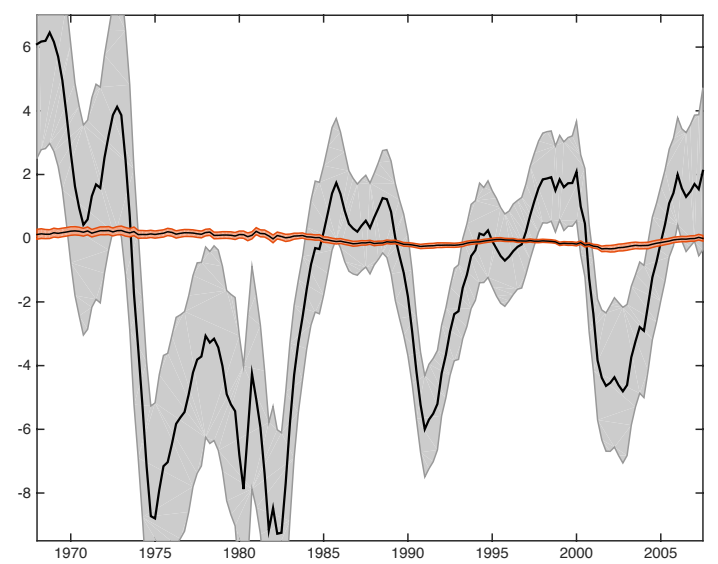

Net Wealth: Real Rate

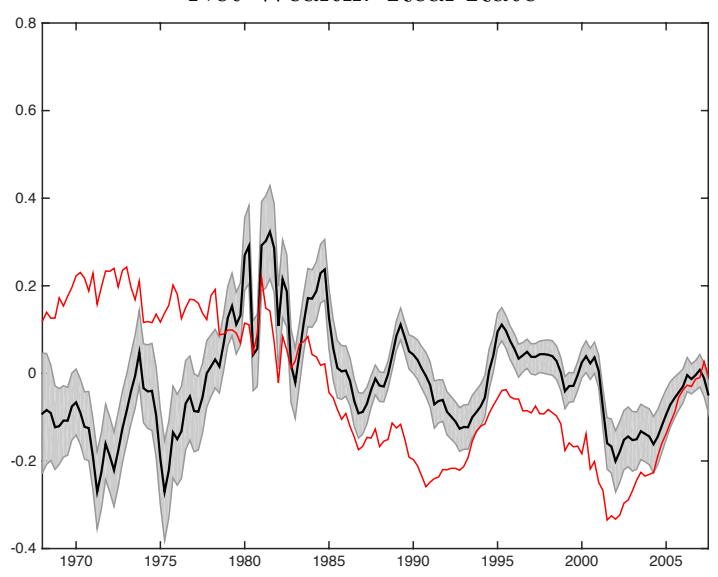

Interest Rate

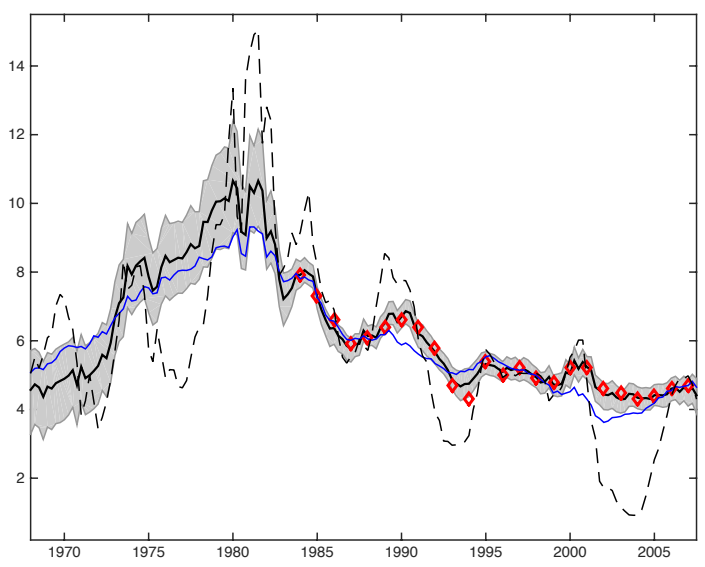

Net Wealth: Taxes

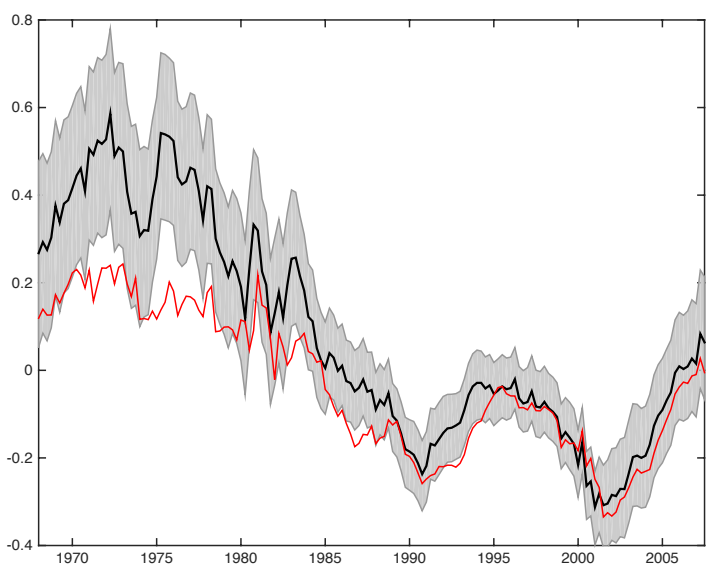

Net Wealth: Excess Return

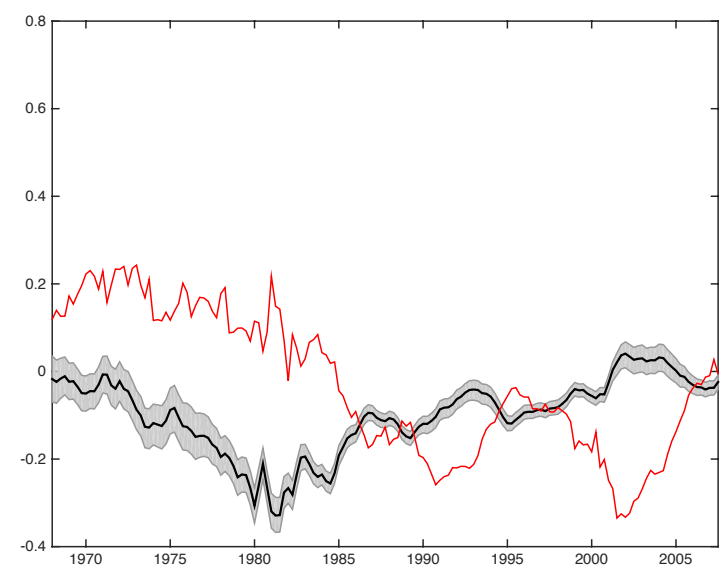

Figure 3: Model Predictions

The top figures show the predicted evolution of long-term expectations for inflation and nominal interest rate. Median predictions are denoted by the solid black line, while the grey area measures the $95 \%$ credible interval; the red diamonds denote 5-10 survey forecasts from Blue Chip Economics; the dashed black line denotes actual variables. The other panels show the evolution of consumption net of wealth (grey), net wealth (red), and its three subcomponents. 
Inflation

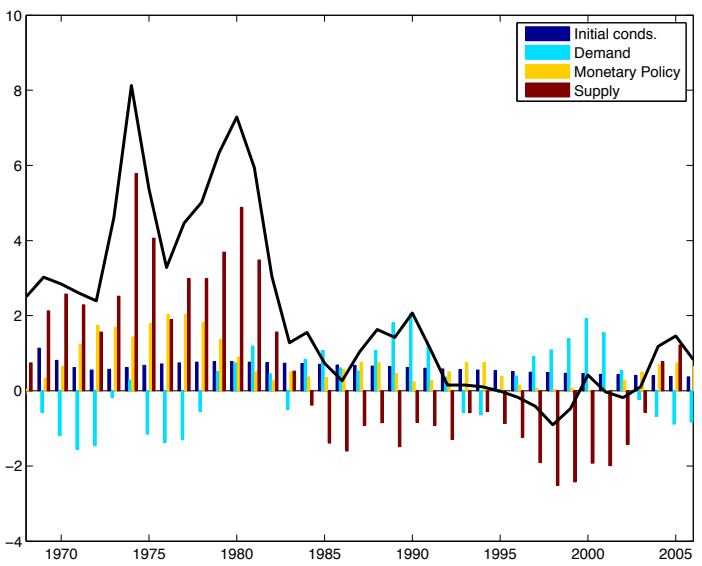

5-10 years ahead Inflation Expectations

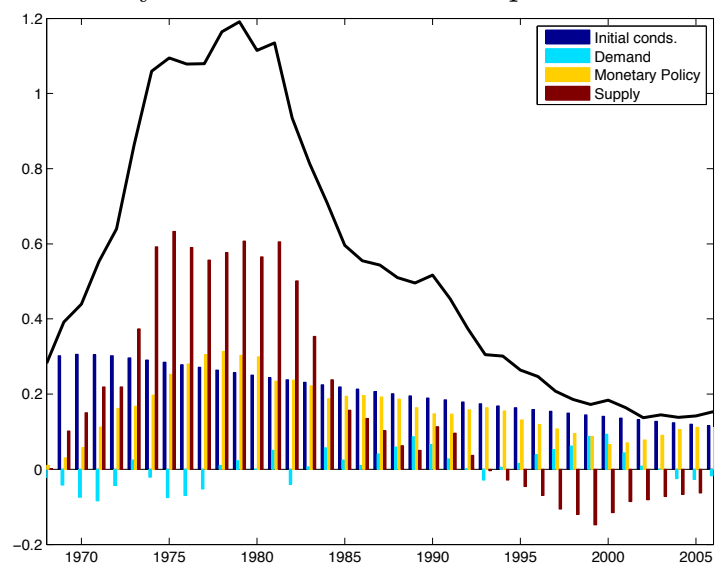

Output Gap

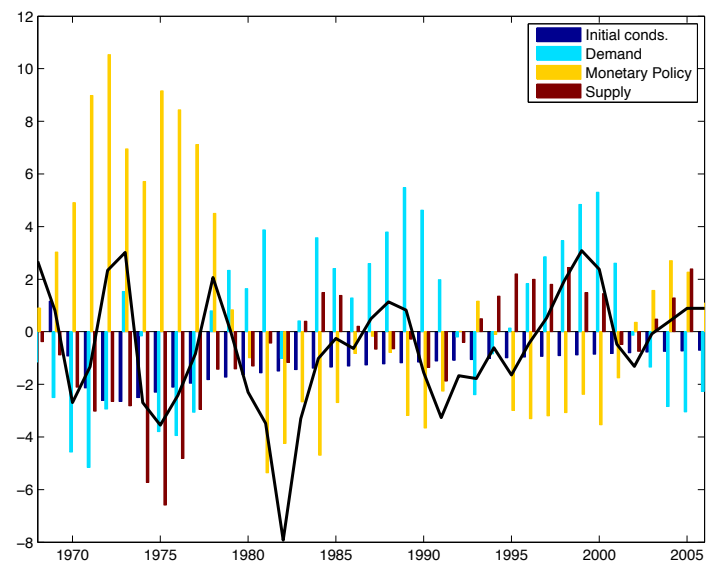

Interest Rate

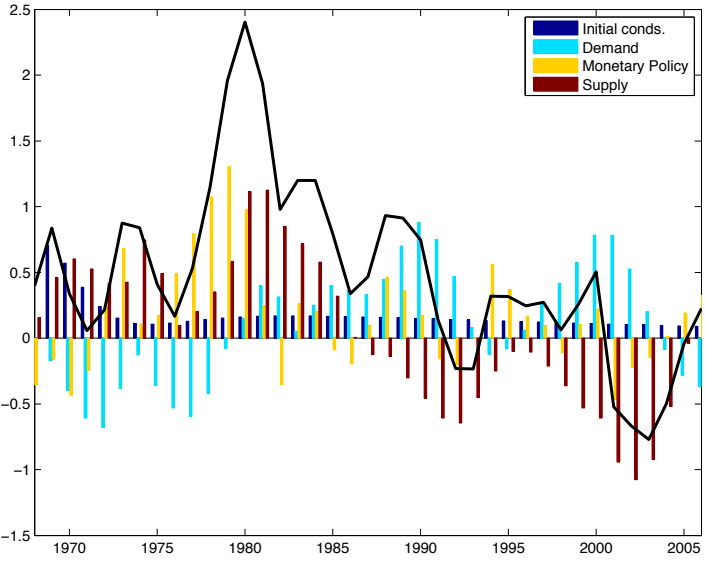

5-10 years ahead Interest Rate Expectations

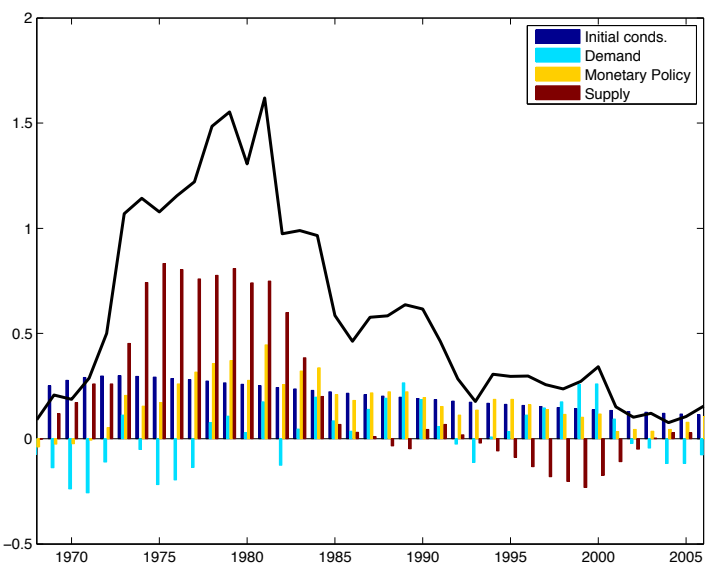

Net Wealth

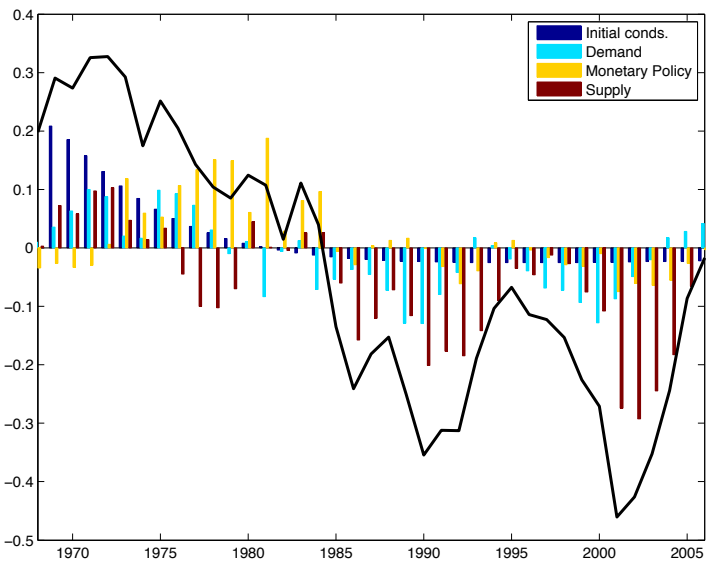

Figure 4: Shock Decomposition

The panels show the decomposition of selected variables calculated at the posterior mode. Data are plotted at an annual frequency; inflation is expressed in term of a four-quarter average; interest rate; output gap, net wealth and expectations are the fourth-quarter realizations (not annualized). 
Debt-to-output ratio of $120 \%$

Debt-to-output ratio of $200 \%$

Inflation: Standard Deviation (annualized)
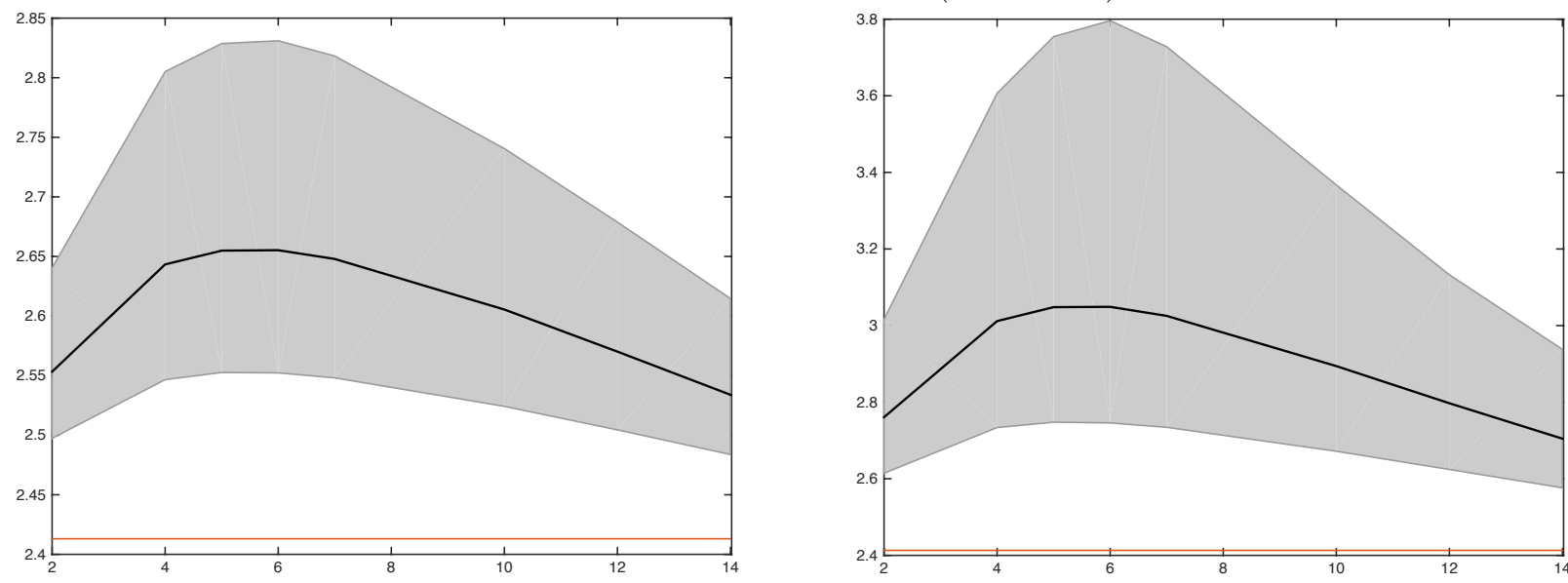

Output Gap: Standard Deviation
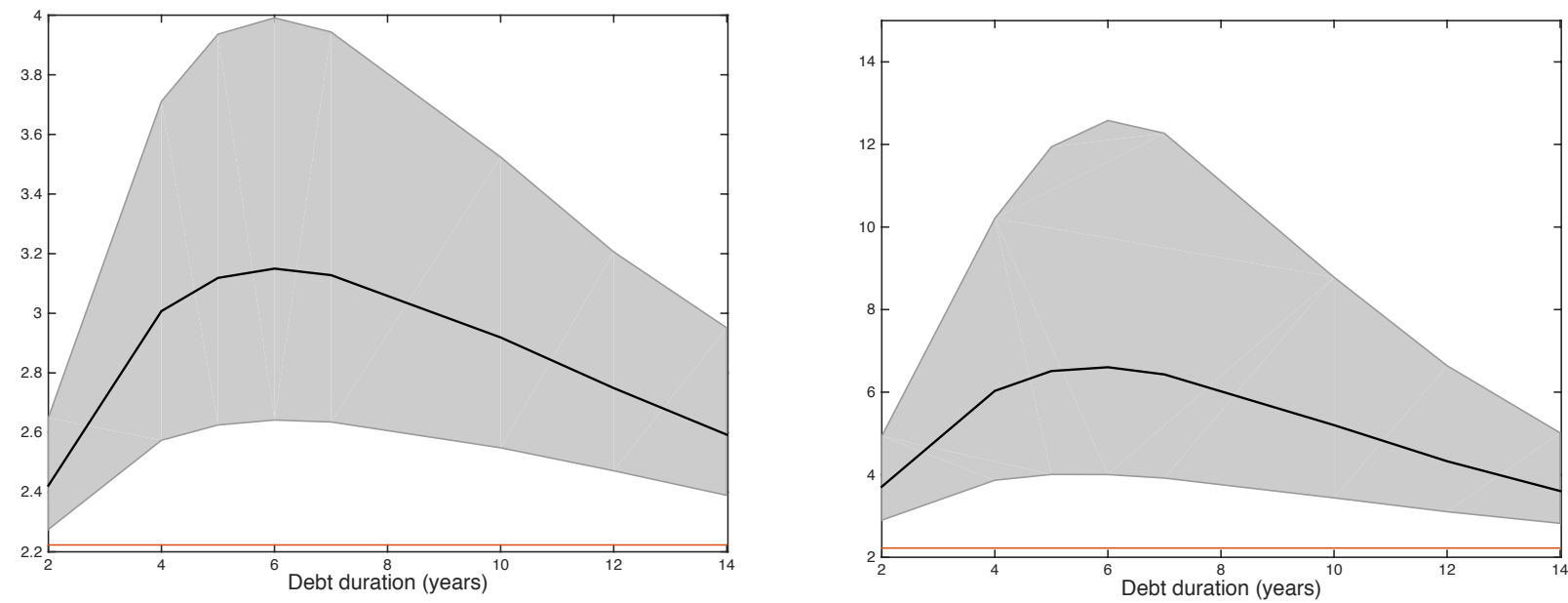

\section{Figure 5: Volatility Frontiers}

The left panels show the volatility of inflation and output gap with a debt-to-output ratio of $120 \%$, for different average durations of debt. The right panels show an economy with debt-to-output ratio of $200 \%$. The red line denotes the sample volatility. The frontiers are computed using the parameters' posterior distribution; the grey area includes the $95 \%$ posterior intervals, while the black solid line describes the median. 
Inflation and 5-10 years-ahead Inflation Expectations
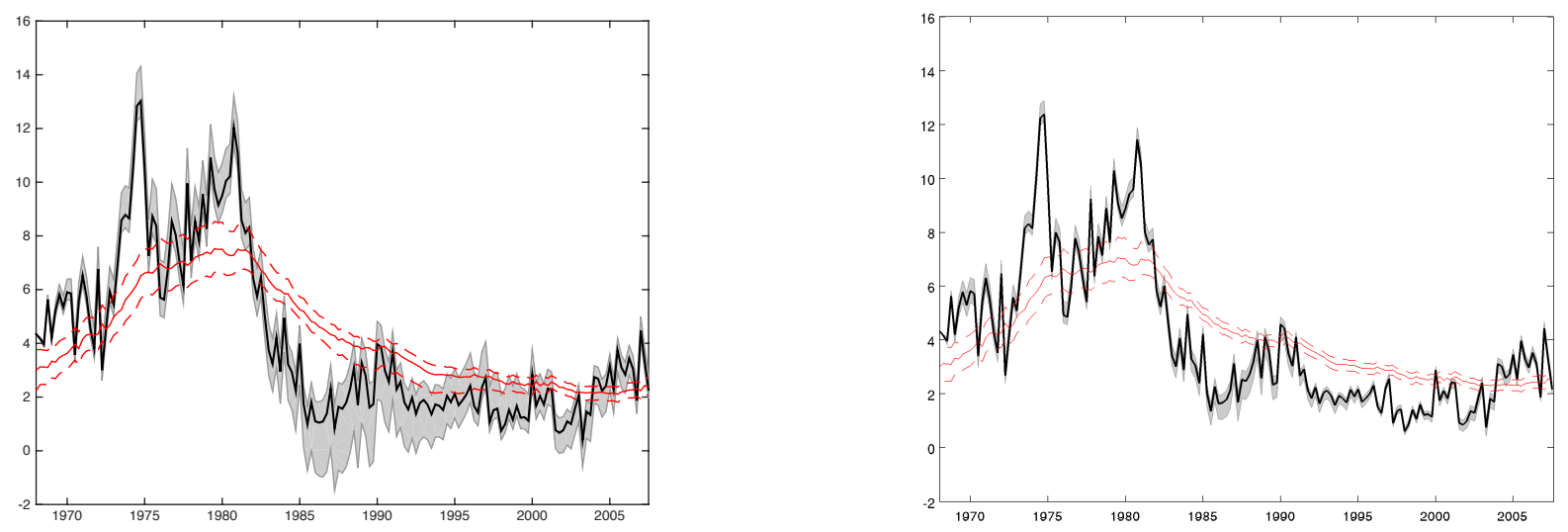

Interest Rate and 5-10 years-ahead Interest Rate Expectations
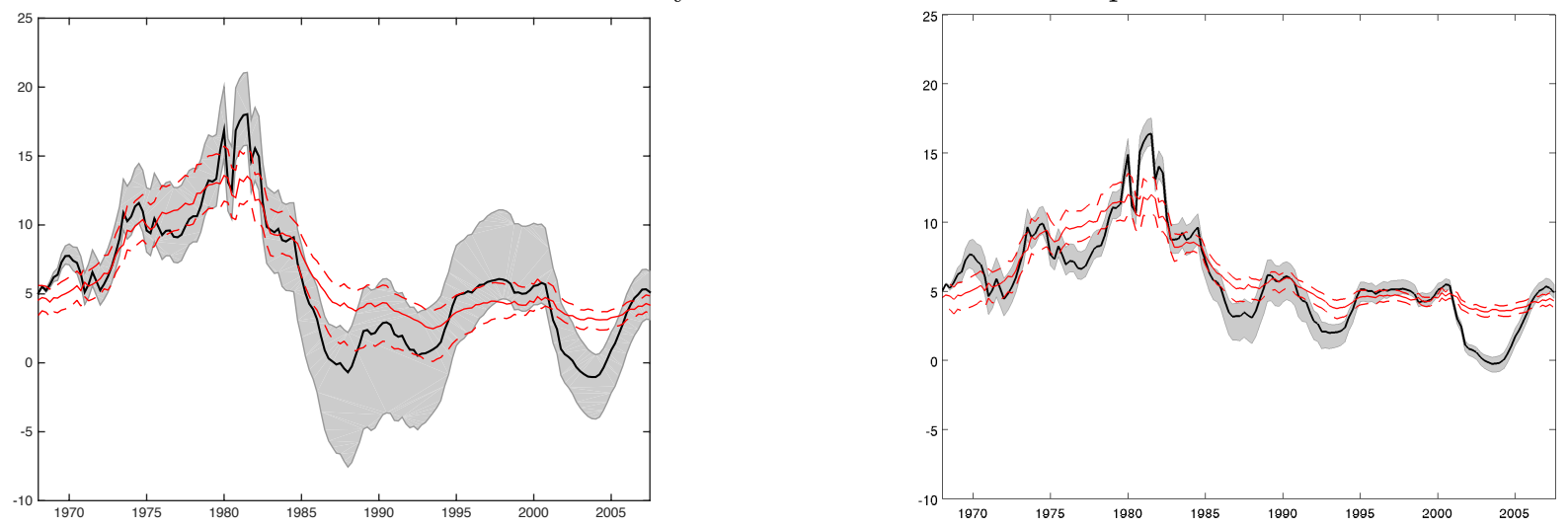

Output Gap and Net Wealth
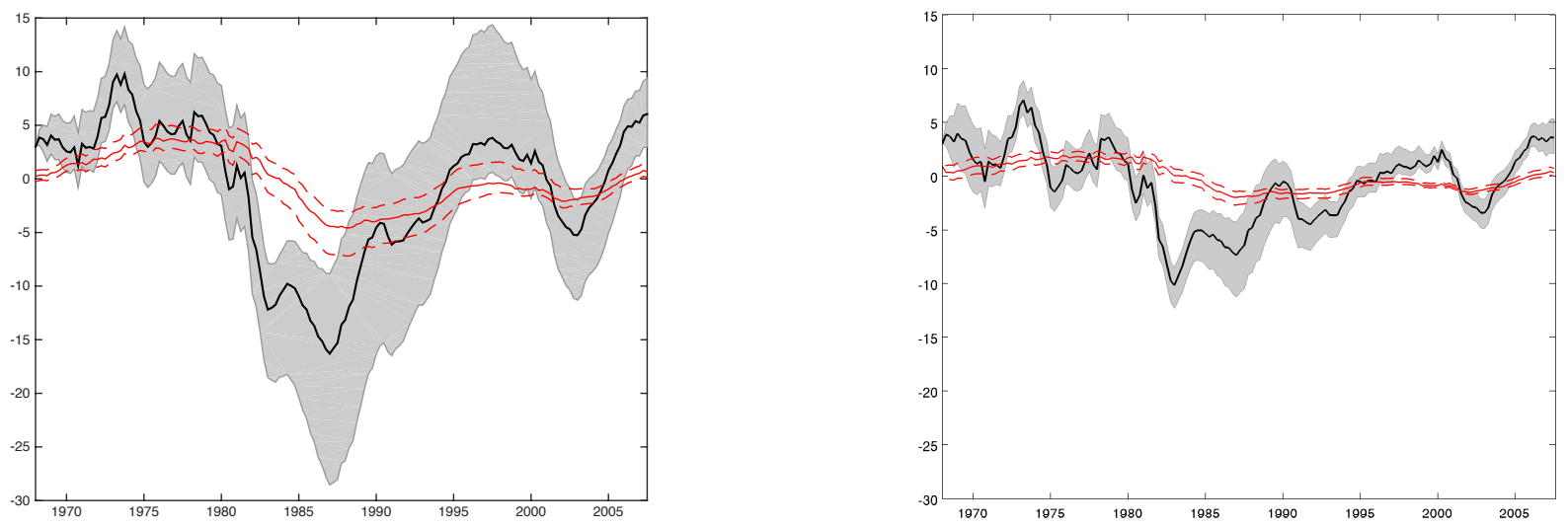

\section{Figure 6: Counterfactuals}

The panels show the evolution of selected variables in two counterfactual economies. Inflation, interest rate and output gap are denoted by solid black lines; expectations and net wealth are shown in red solid lines. The 95th posterior intervals are defined by the grey area and the dashed red lines respectively. The left panels show an economy with $200 \%$ debt-to-output ratio and baseline average maturity of debt. The right panels show an economy with $200 \%$ debt-to-output ratio and 14-years average maturity of debt. 